\title{
Importance of Well Spacing and Orientation for Multi-Lateral Pads on Production: Learnings from Production Analysis and Numerical Modelling of the Mannville Coal Measures, South Central Alberta
}

\author{
Amanda M. M. Bustin, R. Marc Bustin \\ Department of Earth, Ocean, and Atmospheric Sciences, The University of British Columbia, Vancouver, Canada \\ Email: abustin@eoas.ubc.ca
}

How to cite this paper: Bustin, A.M.M. and Bustin, R.M. (2018) Importance of Well Spacing and Orientation for Multi-Lateral Pads on Production: Learnings from Production Analysis and Numerical Modelling of the Mannville Coal Measures, South Central Alberta. Engineering, 10, 368-398.

https://doi.org/10.4236/eng.2018.107027

Received: April 13, 2018

Accepted: July 7, 2018

Published: July 10, 2018

Copyright $\odot 2018$ by authors and Scientific Research Publishing Inc. This work is licensed under the Creative Commons Attribution International License (CC BY 4.0).

http://creativecommons.org/licenses/by/4.0/

\begin{abstract}
The modelling results from numerical simulations of the Early Cretaceous, Mannville coal measures with anisotropic permeability provide insights into development strategies not readily visualized or otherwise intuitive. The complex relationships between water and gas production, the contribution from multiple coal seams as well as from organic rich shales, and the impact of well interference combined with anisotropic fracture permeability are investigated through a series of numerical simulations of four well-pads (on the corners of a square mile of land with decreasing well spacing from 1, 3, to 4 laterals per pad). After 25 years of production, the two pads with optimally-oriented laterals with respect to the fracture permeability anisotropy produce $61 \%$ of the recovered gas for the 1 lateral/pad model, $52 \%$ for the 3 laterals/pad model, and $50 \%$ for the 4 laterals/pad model. Downspacing has a greater impact on increasing the gas production from pads with the poorly-oriented main laterals than from the pads with the optimally-oriented main laterals. The cumulative gas production at the end of the 25 year history is $4.2 \%$ higher for an optimally-oriented pad (pad1) and 1.1 $\times$ higher for a poorly-oriented pad (pad3) for a model with 4 laterals/pad than 3 laterals/pad and an optimally-oriented pad is $1.1 \%$ higher for an optimally-oriented pad and $1.5 \times$ higher for a poorly-oriented pad for a model with 3 laterals/pad than 1 lateral/pad. Although downspacing from 3 to 4 laterals/pad has a greater impact on increasing the cumulative gas production from optimally-oriented pads than downspacing from 1 to 3 laterals/pad, the lower impact on poorly-oriented pads results in a lower total increase the cumulative gas production from the four pads. At the
\end{abstract}


end of the 25-year production history, 9.0\% more gas is recovered for the 4 lateral/pad model than the 3 lateral/pad model, which predicts $1.2 \times$ more gas than the 1 lateral/pad model. The recovered shale gas exceeds the recovered coal gas after $\sim 7$ years of production. The higher contribution of produced coal gas predicted due to downspacing results from a higher contribution of recovered gas from the main coal seam, while the contribution from the minor coal seams is lower. Downspacing has a minimal impact on the cumulative water production; after 25 years of production a difference of $1.0 \%$ is predicted between models with 4 and 3 laterals/pad and 1.7\% between models with 1 and 3 laterals/pad. While downspacing increases the cumulative water production for the poorly-oriented pads ( $1.1 \times$ for 3 to 4 laterals/pad and $1.3 \times$ for 3 to 1 lateral/pad after 25 years), the cumulative water production for the optimally-oriented pads is lower over the majority of the production history (after $\sim 4$ years and 3.2\% lower after 25 years for 3 to 4 laterals/pad and after $\sim 6$ months and $1.1 \times$ lower after 25 years for 1 to 3 laterals/pad).

\section{Keywords}

Coal Bed Methane, Gas Shales, Multi-Lateral Well Pads, Spacing and

Orientation of Laterals, Reservoir Modeling, Unconventional Reservoirs

\section{Introduction}

Designing and implementing strategies for coalbed methane field development in complex coal measures require evaluation of the interplay between geology, reservoir properties, well design, completions, and economics. Numerical simulations provide a powerful tool to predict reservoir performance and evaluate different potential development scenarios prior to or during early field development. Optimising field development of the producing Upper Mannville Group coal measures in the Western Canadian Sedimentary Basin in south-central Alberta is particularly challenging due to permeability anisotropy of the coals and contribution of multiple coals seams and organic rich shales to production.

The Mannville coalbed methane resource occurs over a very large geographic area of southern and central Alberta and in equivalent strata in British Columbia (Figure 1). The total estimated coal gas resource in place is about $325 \mathrm{TCF}^{1}$ in the Mannville Formation [1]. Exploration for coalbed methane in the Upper Mannville Group commenced in the mid-1990s and to date about 1 TCF of gas has been produced. Current production is about $800 \mathrm{mmcf} / \mathrm{day}$, almost all of which is from a fairway of wet coals $\left(\mathrm{S}_{\mathrm{w}}>0\right)$ about $4000 \mathrm{~km}^{2}$ in central Alberta' referred to as Corbett (Figure 1). In the Corbett area, coal gas is produced from about 200 multilateral horizontal wells, spaced mainly at $3-4$ wells per mile ${ }^{2}$ $\left(2.59 \mathrm{~km}^{2}\right.$; Figure 1$)$. The horizontal wells are completed mainly in the thickest seam in the succession and are orientated NW-SE, N-S, and E-W with the

${ }^{1} 1$ trillion cubic feet $\left(2.83 \mathrm{E} 10 \mathrm{~m}^{3}\right)$. 

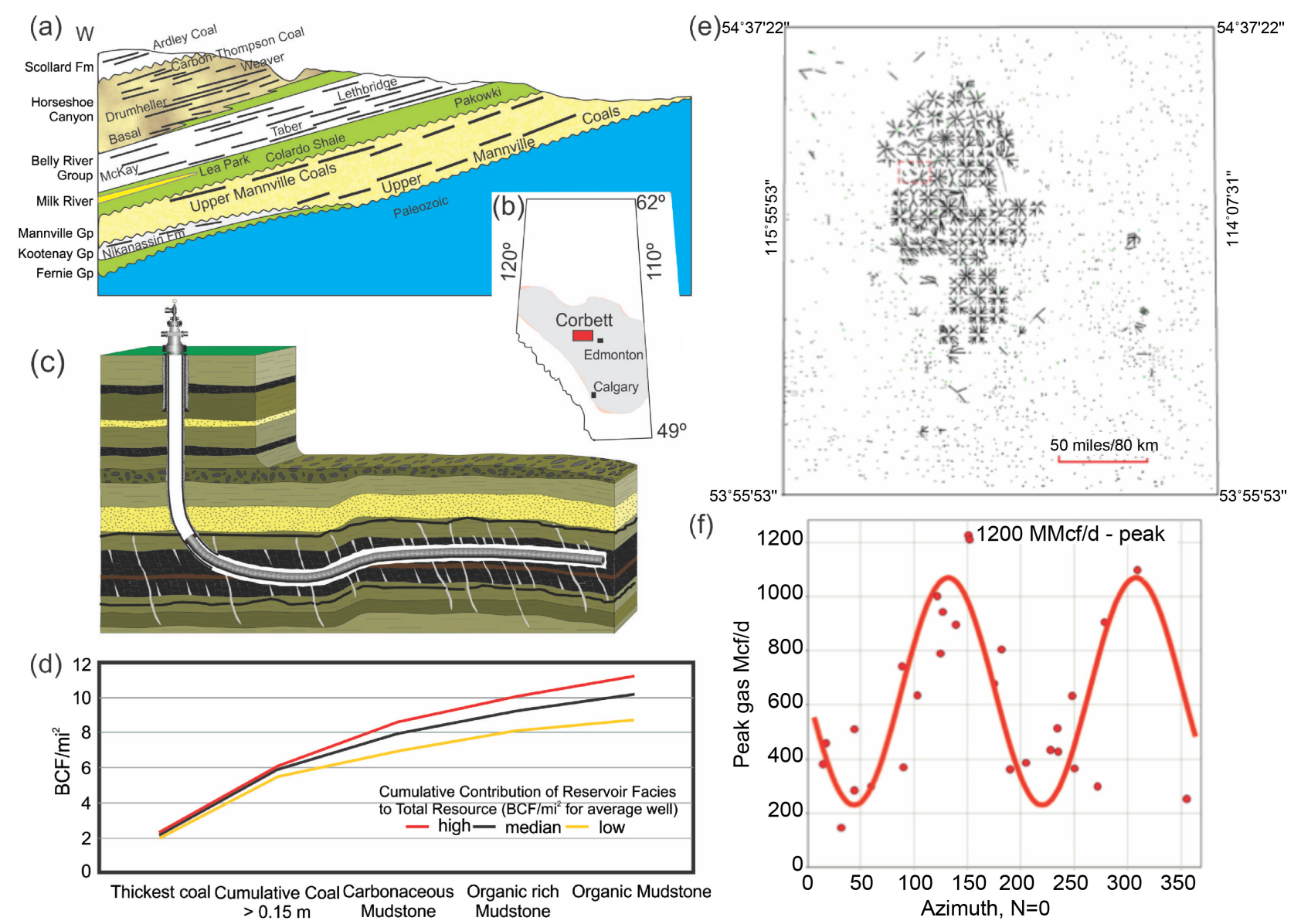

Figure 1. (a) Schematic cross-section across the Western Canadian Sedimentary Basin (modified from [2]); (b) Mannville coal distribution in Alberta shown as the grey region and the location of the Corbett fairway, shown as the red rectangle (modified from [3]); (c) Schematic diagram of a single horizontal well, 1000 - $1600 \mathrm{~m}$ long, drilled and completed in the main (i.e. thickest) coal seam in the sequence (modified from [4]); (d) Cumulative resource by BCF/section for the P10, P50, and P90 gas contents showing the contribution of the main coal seam, all coal seams $>0.15 \mathrm{~m}$, and the shales (variably organic mudstones) for the Mannville coal measures (modified from [5]); (e) Location of horizontal wells (black radiating lines) and vertical wells (black dots) in the Corbett fairway; (f) The variation in production with lateral azimuth for horizontal wells located in the red square of plot (e). The highest production is from wells oriented perpendicular to the face cleat direction (i.e. the direction of maximum fracture permeability; modified from [4]).

horizontal legs between 1000 and $1500 \mathrm{~m}$ in length (Figure 1). The gas production in the Corbett area varies systematically with the orientation of the laterals due to the anisotropy of the fracture permeability (Figure 1). Outside the Corbett fairway, commercial production rates have rarely been achieved irrespective of the drilling and completion strategies employed.

In quantifying reserves and field development in the Mannville producing fairway, reserves and production have generally been considered limited to the main coal seam (1.3 - $4.5 \mathrm{~m}$ thick) and in which the horizontal wells are drilled and completed (Figure 1). However, several thinner ( 1 m) minor coal seams occur in the immediate over and underlying stratigraphy, which account for $63 \%$ of the total calculated gas-in-place in the Upper Mannville coals (Figure 1; [6]). Additionally, gas generally not considered in the total gas-in-place calcula- 
tions or as contributors to production, occurs within organic rich fine-grained strata (referred to here as gas shales) interbedded with, as well as over- and under-lying the coal seams. Including the gas shales further increases the total gas-in-place 1.7 times (Figure 1; [5]). Through numerical modelling [7] then predicted that, for a model with average parameter values, 1.4 times $(x)$ more gas and 3.0 $\times$ more water is produced when the minor coal seams are included, while also including shale beds predicts $1.7 \times$ more gas and $2.5 \times$ more water after 25 years of production from a $1000 \mathrm{~m}$ long, horizontal well than when only the main coal seam is considered. A parametric analysis was also completed quantifying the impact of the coal and shale properties on the producability of the Mannville reservoir [8]. The modelling predicts $14 \times$ more gas and $13 \times$ more water after 10 years of production when the coal fracture permeability is increased between end-member values $(0.5$ and $31 \mathrm{md})$ and the shale fracture permeability, which is the parameter with the next greatest impact on production predicts $1.7 \times$ more gas and $2.1 \times$ more water when increased between end-member values $\left(1 \times 10^{-4}\right.$ and $\left.0.01 \mathrm{md}\right)$.

Expanding the models to including multi-lateral well-pads, in this study, the impact of decreasing the spacing between lateral wells (i.e. downspacing) on the production of the Mannville coal measures is investigated through a series of numerical models. This study further investigates the importance of the orientation of the laterals within the anisotropic permeability field and the impact of well interference. Experimental and field data from the Mannville coal measures and adjacent shales in the Corbett region in south-central Alberta are used as model inputs for a general equation-of-state reservoir simulator (CMG-GEM). Our study builds on and extends the work of [9] who used numerical simulations to predict the producability of the main Mannville seam from parallel laterals. Although our study is based on the metrics of the Mannville coal measures, the results are instructive and relevant to other coalbed methane developments where multiple coal seams and gas bearing shales occur.

\section{Model Parameters}

The variation in production of the Mannville reservoir from four orthogonal multi-lateral pads, with spacings of 1, 3, and 4 laterals/pad, was investigated using the commercial CMG's GEM advanced general equation-of-state compositional simulator to understand the impact of well spacing and orientation (Figure 2). The production from four well pads within a square mile of land $(1600 \times 1600 \mathrm{~m})$ in the center of a $6400 \times 6400 \mathrm{~m}$ model were modeled for a 25 year history. The square drainage area in the multi-lateral pad models was discretized into $50 \mathrm{~m}$ grid blocks. The model parameters for this study were collected from three different sources: producing companies in house databases, our database at UBC, and new laboratory tests on coal and shale samples collected from three Mannville wells: 12-31-62-05W5, 15-27-62-06W5, and 16-10-62-06W5. All model parameters, except the number of laterals per pad were kept at their 

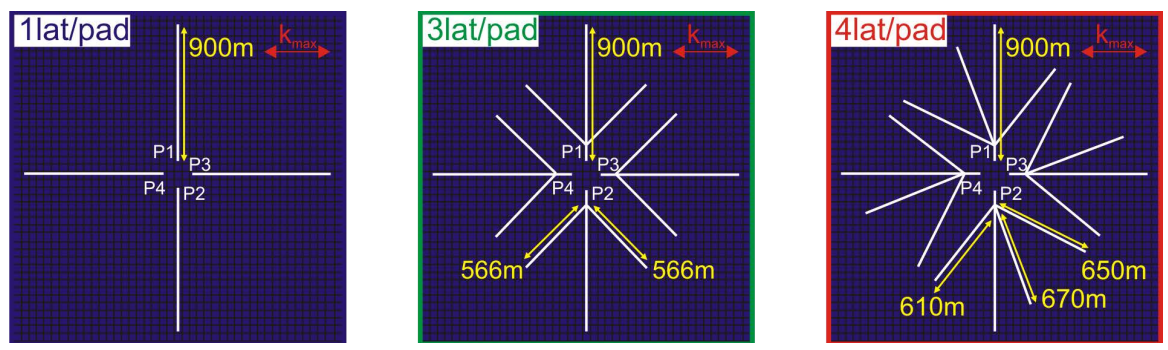

Figure 2. Well design for the 1 lateral/pad model (1 lat/pad), 3 laterals/pad model (3 lat/pad), and 4 laterals/pad model (4 lat/pad). The lengths of the laterals are shown on the plots. The direction of the maximum coal fracture permeability $\left(\mathrm{k}_{\max }\right)$ is indicated. P1-pad1; P2—pad2; P3-pad3; P4-pad4.

average values (Table 1). The fracture permeabilities were held constant during the modelling (i.e. dynamic changes in permeability with effective stress were ignored). Two of the main laterals are oriented within the model perpendicular to the direction of the maximum coal fracture permeability, which is anisotropic. Production from the Corbett indicates a directional component of system permeability, with permeability $2-3$ times $(x)$ higher in the direction parallel to a developed face cleat $\left(\mathrm{N} 25^{\circ} \mathrm{E}\right)$. The coal permeability in the models was thus input as three times higher in one horizontal direction than the other horizontal direction $\left(\right.$ at $90^{\circ}$ ) and the vertical direction (Figure 3). The shale fracture permeability was assumed to be an order of magnitude higher in the horizontal than the vertical direction to account for the commonly observed transversely isotropic intrinsic shale symmetry (Figure 3 ).

Similar to Bustin and Bustin (2017), the depth and thickness of the horizontally stacked coal seams in the models were determined from interpretations of logs from well 16-10-62-06W5 (Table 2) with layers (beds) of gas shales interbedding and over- and under-lying the coal seams. A cross-section of the model showing the geometry of the coal versus shale layers is shown in Figure 3. The historically produced water from the Mannville coals indicates that any contribution due to free gas within the porosity of the coal matrix would be minor and hence free gas was not considered in the models. Therefore, the original-gas-in-place (OGIP) within the wet $\left(S_{w}>0\right)$ Mannville Group is in the adsorbed state (i.e. no free gas) and the gas in productive area is almost entirely methane with at most a few percent carbon dioxide, while the cleats and fractures are 100\% water-saturated (Bustin and Bustin, 2016a; 2017). As a consequence of the symmetry of the model, the production results for pads 1 and 2 (pad1 and pad2) are essentially equal $(<0.5 \%)$, as are the results for pads 3 and 4 (pad3 and pad4). Therefore, only the results from pad 1 and pad 3 are discussed.

\section{Results and Discussion}

The gas and water production from a multi-well pad model with one lateral per pad over a 25 year history is first presented, followed by the results from a multi-well pad model with three laterals per pad, and then with four laterals per 
Table 1. The input parameters used during the modelling.

\begin{tabular}{|c|c|c|c|c|c|c|}
\hline \multirow{2}{*}{ Parameter } & \multicolumn{2}{|c|}{ Reservoir } & \multicolumn{2}{|c|}{ Coal } & \multicolumn{2}{|c|}{ Shale } \\
\hline & $\mathrm{n}$ & Ave & $\mathrm{n}$ & Ave & $\mathrm{n}$ & Ave \\
\hline Temperature ${ }^{\circ} \mathrm{C}$ & 130 & 42 & & & & \\
\hline Pressure gradient $\mathrm{kPa} / \mathrm{m}$ & 279 & 8.2 & & & & \\
\hline Water saturation $\%$ & & 99 & & & & \\
\hline Crit water saturation \% & & 60 & & & & \\
\hline Bottom hole pressure $\mathrm{kPa}$ & & 200 & & & & \\
\hline Density g/cc & & & 354 & 1.4 & 35 & 2.2 \\
\hline Langmuir volume cc/g & & & 45 & 13.7 & 12 & 1.5 \\
\hline Langmuir pressure $\mathrm{MPa}$ & & & 45 & 5.7 & 12 & 6.2 \\
\hline Matrix perm md & & & & $1 e-3$ & & $1 e-5$ \\
\hline Diffusion $\mathrm{cm}^{2} / \mathrm{s}$ & & & & 0.05 & & $8 e-3$ \\
\hline Matrix porosity $\%^{a}$ & & & & $1 e-4$ & & $1 \mathrm{e}-4$ \\
\hline Eff fracture spacing $m$ & & & & 0.5 & & 10 \\
\hline Max horiz fracture perm md & & & 110 & 3.8 & & $1 e-3$ \\
\hline Min horiz fracture perm md & & & & $=\mathrm{K}_{\max } / 3$ & & $=\mathrm{K}_{\max }$ \\
\hline Vert fracture perm md & & & & $=\mathrm{K}_{\max } / 3$ & & $=\mathrm{K}_{\max } / 10$ \\
\hline Fracture porosity $\%$ & & & & 0.01 & & $1 \mathrm{e}-4$ \\
\hline
\end{tabular}

${ }^{a}$ Note that the matrix porosity values listed above were assumed during the modelling, due to the bound matrix water (matrix $S_{w}$ assumed to be zero by the model), and are not the measured values.

Table 2. Depth to top of coal seams and seam thickness in the Mannville well.

\begin{tabular}{ccc}
\hline & \multicolumn{2}{c}{ 16-10-62-6w5 } \\
\cline { 2 - 3 } Seam & Depth $(\mathrm{m})$ & Thick $(\mathrm{m})$ \\
\hline U1 & 945.3 & 0.9 \\
U2 & 957.5 & 0.7 \\
U3 & 959.3 & 0.7 \\
M & 980.0 & 4.0 \\
L1 & 986.0 & 1.8 \\
L2 & 994.6 & 1.0 \\
\hline
\end{tabular}

pad. The impact of downspacing on the gas and water production, the produced coal gas versus produced shale gas, and variations in produced gas between the main and minor coal seams are then discussed.

\subsection{Multi-Well Pad Model with One Lateral per Pad}

The multi-well pad model with a well spacing of 1 lateral/pad, consists of two $900 \mathrm{~m}$ laterals through the main Mannville coal seam optimally-oriented in the direction of maximum coal fracture permeability (pad3 and pad4; Figure 1) and two $900 \mathrm{~m}$ laterals poorly-oriented in the direction perpendicular to the maximum coal fracture permeability (pad1 and pad3; Figure 1). 


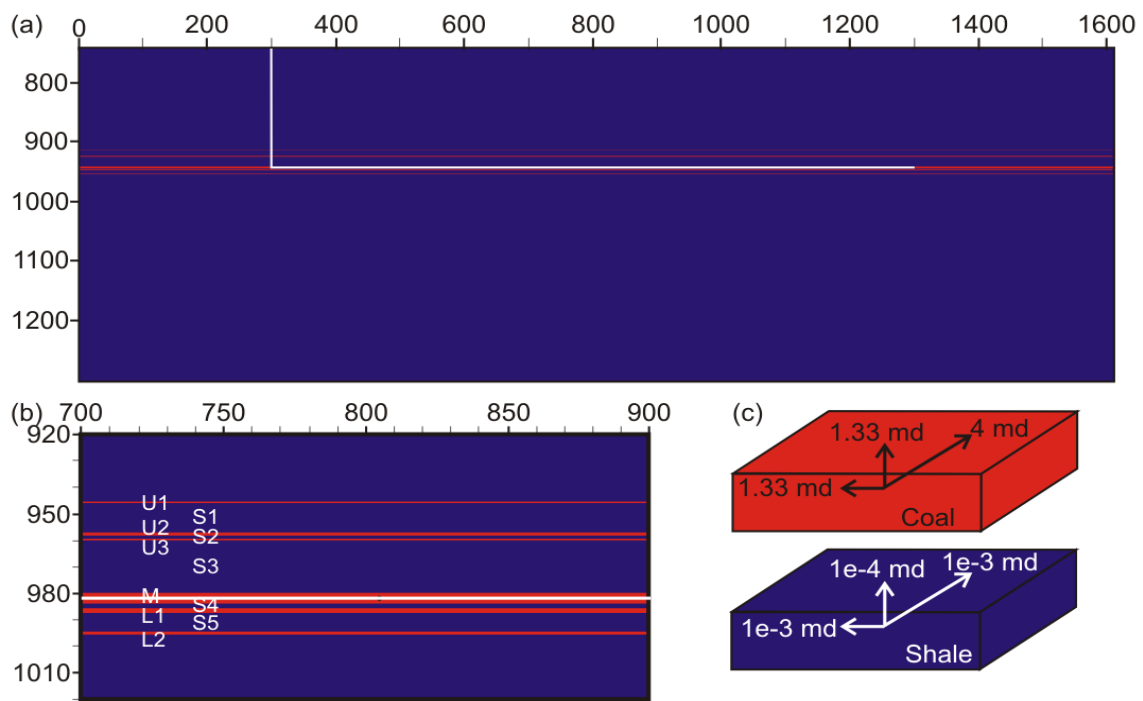

Figure 3. Cross-section of the model through a plane containing the wellbore showing the geometry of the coal seams (red) versus shale layers (blue). (a) Cross-sectional view of the full model and (b) close-up of the reservoir. The labels for the coal seams and interbedded shale layers are shown on (b). The location of the horizontal well is shown by thin white lines. (c) Three-dimensional schematic illustrating the coal (top) and shale (bottom) fracture permeability anisotropy.

\subsubsection{Gas Production}

As a consequence of the anisotropy of the coal fracture permeability, the initial peak gas production rate is $1.5 \times$ higher from the optimally-oriented lateral at pad1 than the poorly-oriented lateral at pad3 (red versus blue solid curves in Figure 4(b)). The lower relative well interference combined with the larger drainage volume for optimal orientations with respect to the coal fracture permeability anisotropy results in a maximum of $1.7 \times$ more produced gas after $\sim 3$ years (1080 days) of production (red versus blue solid curves in Figure 4(a) and green solid curve in Figure 5). After $\sim 3$ years of production, the shorter period of dewatering required for the poorly-oriented laterals, resulting from the lower gas saturation and thus higher relative permeability to water, decreases the difference in cumulative gas production between the optimally- and poorly-oriented laterals to $1.5 \times$ after $\sim 15.5$ years (5630 days) of production. The faster depletion of the poorly-oriented laterals, due to the well interference, then increases the difference to $1.6 \times$ at the end of the 25 year production history.

\subsubsection{Water Production}

The greater impact of well interference on the poorly-oriented lateral at pad3 than the optimally-oriented lateral at pad1 for the 1 lateral/pad model results in faster dewatering for pad 3 and an increasing difference in cumulative water production between the laterals to $2.7 \times$ after 25 years of production (red versus blue solid curves in Figure 4(c) and green dotted curve in Figure 5).

\subsection{Multi-Well Pad Model with Three Laterals per Pad}

The multi-lateral, multi-well pad model with 3 laterals/pad consists of one $900 \mathrm{~m}$ 
(a)

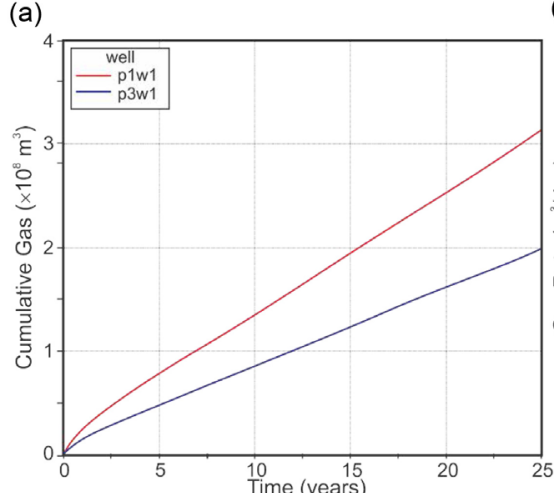

(c)

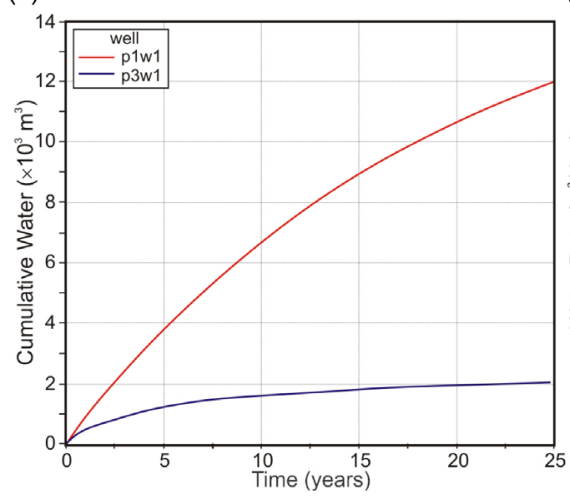

(b)

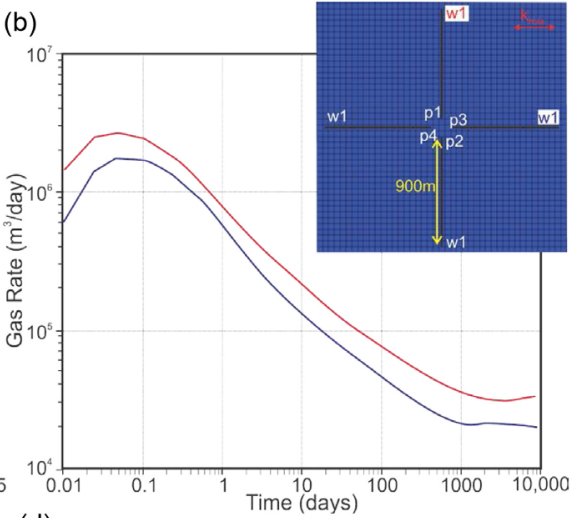

(d)

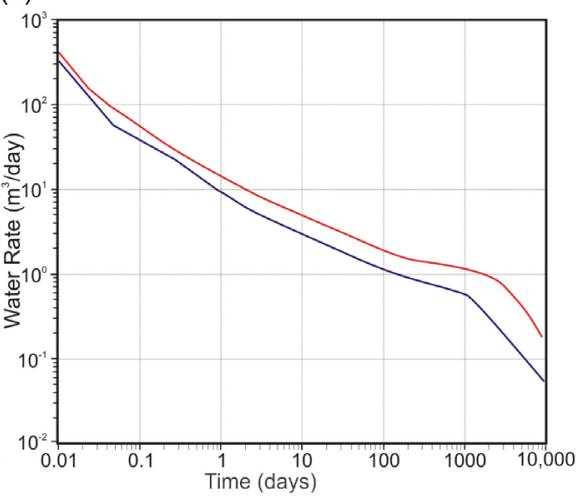

Figure 4. Well design for the 1 lateral/pad model (1 lat/pad), 3 laterals/pad model (3 lat/pad), and 4 laterals/pad model (4 lat/pad). The lengths of the laterals are shown on the plots. The direction of the maximum coal fracture permeability $\left(\mathrm{k}_{\max }\right)$ is indicated. P1-pad1; P2-pad2; P3-pad3; P4-pad Comparison of the gas (top) and water (bottom) cumulative production (left) and production rates (right) simulated for well1 at pad1 (w1p1-red solid curves) and well1 at pad3 (w1p3-blue solid curves) for the 1 lateral/pad model. The locations of the laterals are shown on the inset plot of (b). In the inset plot, the maximum permeability is $\mathrm{N}-\mathrm{S}$ and minimum is $\mathrm{E}-\mathrm{W}$, as shown in Figure 2.

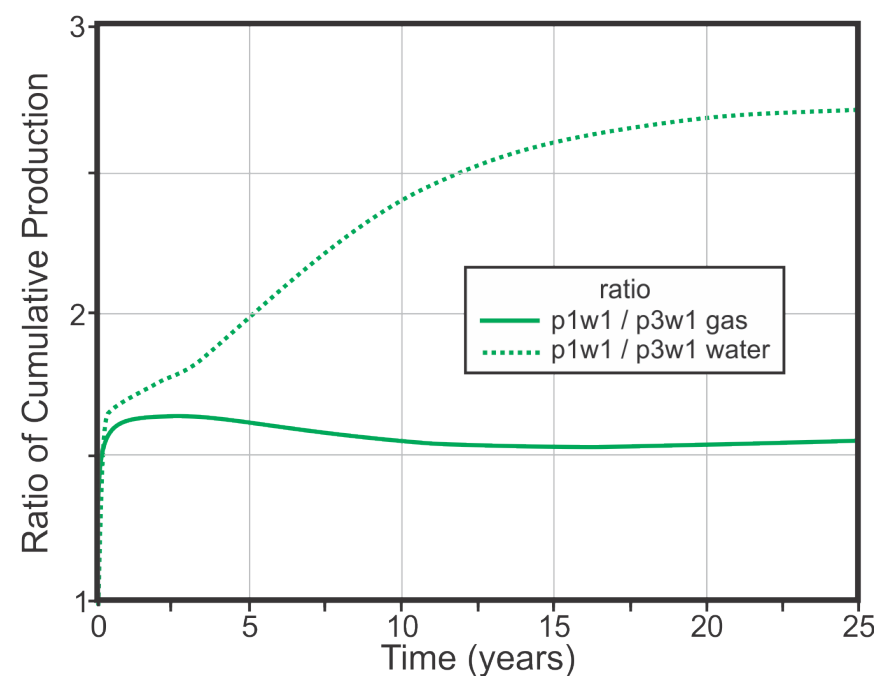

Figure 5. Ratio of cumulative gas production (solid curve) and cumulative water production (dotted curve) for well1at pad1 (p1w1) versus well 1 at pad3 for the 1 lateral/pad model. 
lateral (well1), either optimally-oriented (for pad1, Figure 1) or poorly-oriented (for pad3, Figure 1), and two $566 \mathrm{~m}$ laterals oriented at $45^{\circ}$ to well1 (well2 and well3 in Figure 1). The production histories for the two shorter laterals (well2 and well3) on each pad are essentially equal as a consequence of the symmetry of the model; therefore, only well 2 will be discussed in the following section.

\subsubsection{Gas Production}

The main lateral, optimally-oriented with respect to the coal fracture permeability anisotropy, on a pad with a 3 laterals/pad well spacing (well1 on pad1 or pad2) is predicted to produce a $2.4 \times$ higher initial peak gas production rate and a maximum of $2.7 \times$ more cumulative gas production at the end of the 25 year history than a $45^{\circ}$ lateral (well2 on pad1; red versus orange curves in Figure 6(a) and Figure 6(b) and red curve in Figure 7(a)). In addition to being longer, the main lateral is also more optimally-oriented and hence results in greater interference on the two $45^{\circ}$ laterals. As a result of the well interference, the gas production rate for the $45^{\circ}$ lateral continuously declines following the initial peak gas production rate and the increase in gas production rates following dewatering is absent (orange curve in Figure 6(b)).

(a)

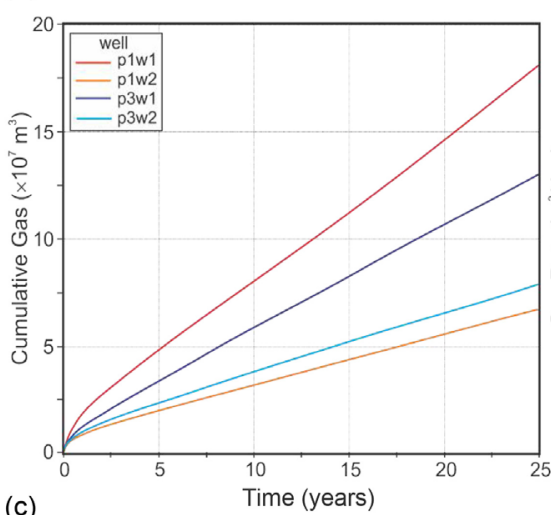

(c)

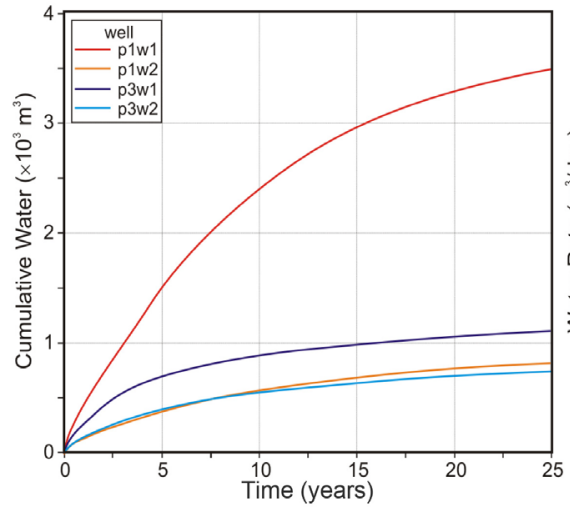

(b)

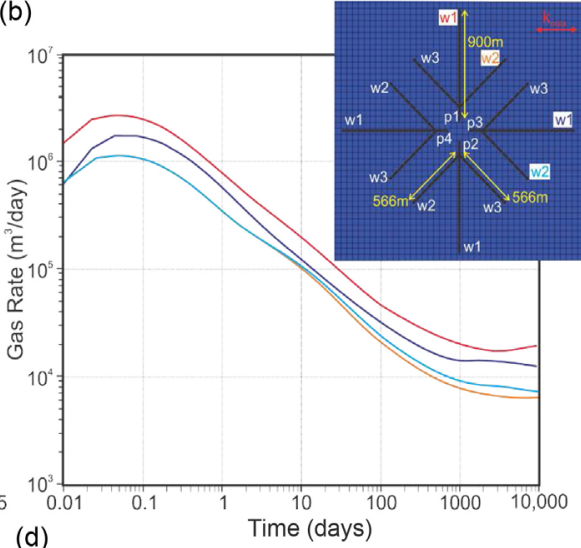

(d)

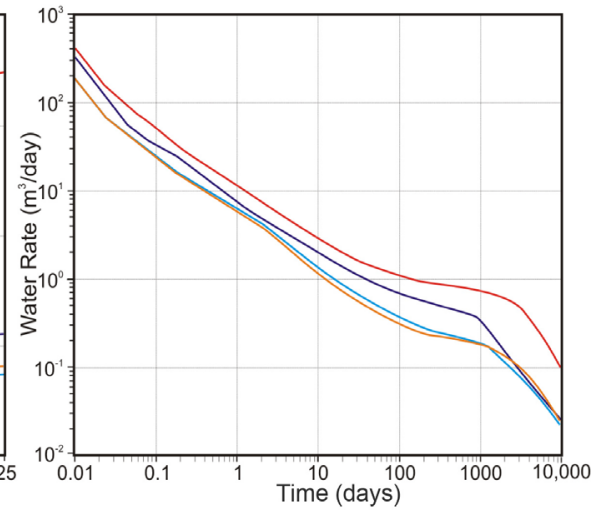

Figure 6. Comparison of the gas (top) and water (bottom) cumulative production (left) and production rates (right) simulated for well1 (p1w1-red curves) and well2 at pad1 (p1w2-orange curves), and well1 (p3w1-blue curves) and well2 at pad3 (p3w2) for the 3 laterals/pad model. The locations of the laterals are shown on the inset plot of (b). In the inset plot, the maximum permeability is N-S and minimum is E-W, as shown in Figure 2. 
(a)

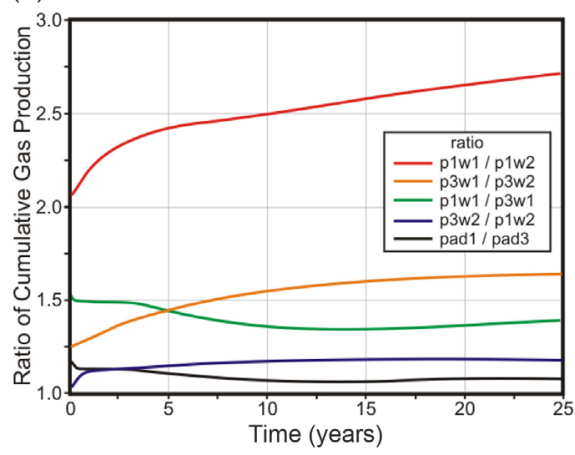

(b)

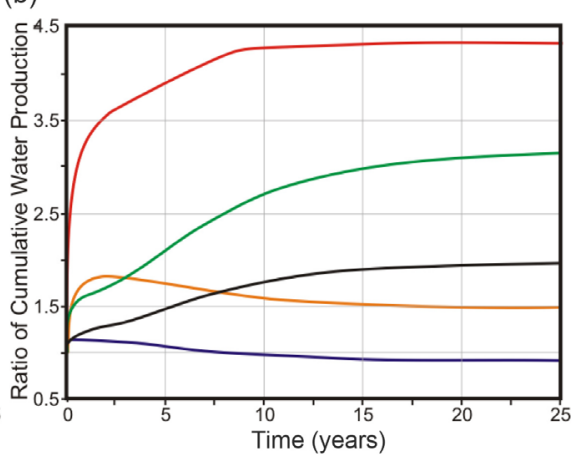

Figure 7. Ratio of cumulative gas production (a) and cumulative water production (b) for well1 (p1w1) versus well2 (p1w2) at pad 1 for the 3 laterals/pad model (red curves); ratio for well1 ( $\mathrm{p} 3 \mathrm{w} 1)$ versus well2 (p3w2) at pad3 (orange curves); ratio for well1 at pad1 versus well1at pad3 (green curves); ratio ofwell2 at pad1 versus well2 at pad3 (blue curves); and the ratio of pad1 versus pad3 (black curves).

Although the $45^{\circ}$ laterals are more optimally-oriented with respect to the coal fracture permeability anisotropy than the poorly-oriented well 1 at pad3, the longer length of the poorly-oriented well1 results in a $1.6 \times$ higher initial peak gas production rate (blue versus light blue curves in Figure $6(\mathrm{~b})$ ). The more optimal orientation of well 2 than well 1 at pad3 then slightly decreases the difference in cumulative gas production between the laterals during the first $\sim 2$ months of production (blue versus light blue curves in Figure 6(a) and orange curve in Figure $7(\mathrm{a})$ ). After which, the difference increases to $1.6 \times$ at the end of the 25 year history as a result of the faster depletion of well 2 than the poorly-oriented well1, due to the greater impact of well interference on decreasing the volume of gas available for drainage.

The optimally-oriented well1 at pad1 predicts a $1.5 \times$ higher initial peak gas production rate (red versus blue curves in Figure 6(b)) and 1.5× higher cumulative gas production than the poorly-oriented well1 at pad3 until 3 years (1030 days) of production (red versus blue curves in Figure 6(a) and green curve in Figure $7(\mathrm{a})$ ). The difference then decreases following dewatering of the poorly-oriented well1 at pad3 to $1.4 \times$ after $\sim 13.5$ years (4991 days) of production, after which the difference increases slightly until the end of the 25 year history, due to the faster depletion of the poorly-oriented well 1 than the optimally-oriented well1 at pad1.

The initial peak gas production rate for a $45^{\circ}$ lateral at pad3 is very slightly $(\sim 10 \%)$ lower than predicted for a $45^{\circ}$ lateral at pad1 (light blue versus orange curves in Figure $6(\mathrm{~b})$ ). The cumulative gas production for a $45^{\circ}$ lateral at pad3; however, is greater than for a $45^{\circ}$ lateral at pad 1 after 1 day of production and is $1.2 \times$ higher after 25 years of production, due to the lower impact of well interference on the $45^{\circ}$ laterals at pad 3 than at pad1 (light blue versus orange curves in Figure 6(a) and blue curve in Figure 7(a)). The difference in cumulative gas production predicted for the $45^{\circ}$ laterals at pad 3 and at pad 1 increases to $1.2 \times$ after $\sim 16$ years of production, after which the slightly faster depletion for the $45^{\circ}$ 
lateral at pad 3 results in a slight decrease in the difference until the end of the 25 year history. Whereas the gas production rate declines continuously from the initial peak rate for well2 at pad1 (orange curve in Figure 6(b)), the gas production rate increases very slightly following dewatering for well2 at pad3 (light blue curve in Figure 6(b)).

The three laterals at pad 1 predict a $1.2 \times$ higher initial peak gas production rate than the three laterals at pad3 (green solid versus dashed curves in Figure 8(b)). The shorter period of dewatering required for pad 3 than pad 1 slightly decreases the difference in cumulative gas production between the pads from 3 to 13 years of production ( $13 \%$ to $6.9 \%$ more produced gas from pad 1 than pad3), following which the faster depletion of pad3 increases the difference to $1.1 \times(9.6 \%)$ at the end of the 25 year history (green solid versus dashed curves in Figure 8(a) and black curve in Figure 7(a)).

\subsubsection{Water Production}

The faster drainage from the longer more optimally-oriented well1 at pad1 predicts a maximum of $4.3 \times$ more produced water than well 2 at pad 1 at the end of the 25 year history (red versus orange curves in Figure 6(c) and red curve in Figure 7(b)). The longer length of the poorly-oriented well1 at pad3 results in a

(a)

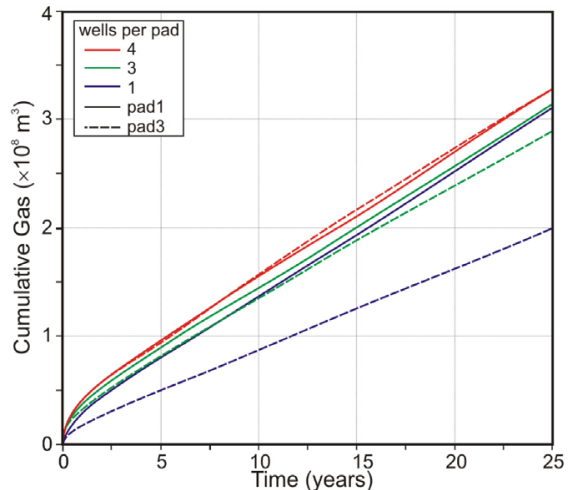

(c)

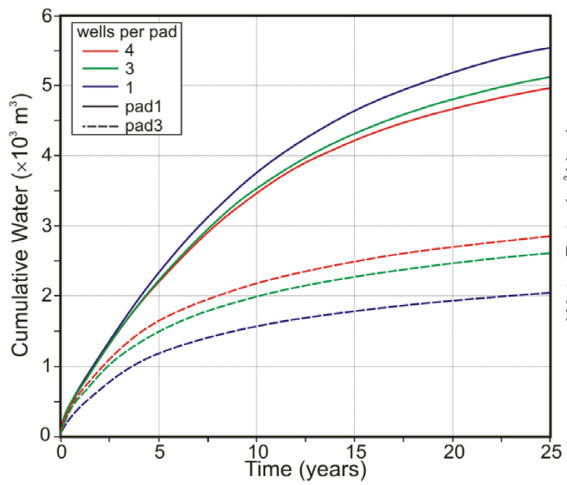

(b)

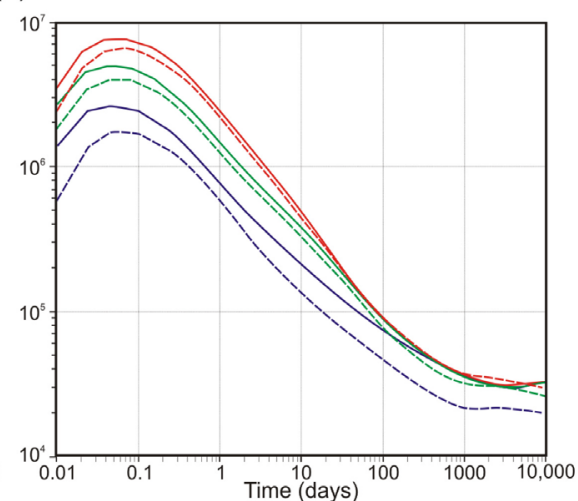

(d)

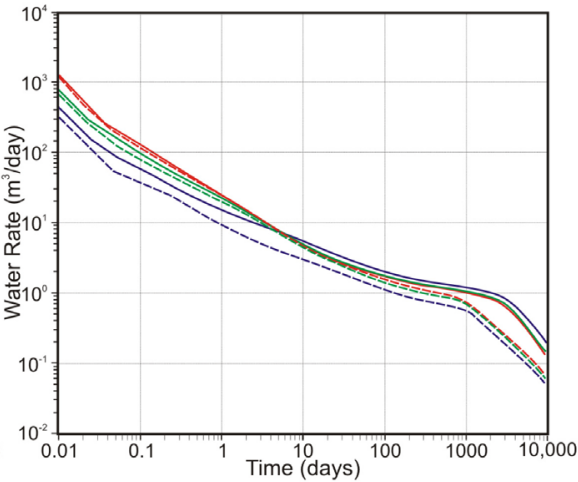

Figure 8. Comparison of the gas (top) and water (bottom) cumulative production (left) and production rates (right) from pad 1 (solid curves) and pad 3 (dashed curves) simulated for the 1 lateral/pad (blue curves), 3 laterals/pad (green curves), and 4 laterals/pad (red curves) models. 
maximum of $1.8 \times$ more produced water after $\sim 2.5$ years of production than the more optimally-oriented, but shorter well2 at pad3 (blue versus light blue curves in Figure 6(c) and orange curve in Figure $7(b)$ ). The slower dewatering for well2 than well1 at pad3, due to the greater relative impact of well interference, decreases the difference in produced water between the laterals to $1.5 \times$ at the end of the 25 year production history.

The faster dewatering of the poorly-oriented well1 at pad3 than the optimally-oriented well 1 at pad 1 for the 3 laterals/pad model increases the difference in cumulative water production between the main laterals, such that well1 at pad 1 produces $3.1 \times$ more water at the end of the 25 year history (blue versus red curves in Figure 6(c) and green curve in Figure 7(b)). The higher gas saturations surrounding well2 at pad1, due to the interference from the optimally-oriented well1, results in a lower relative permeability to water and thus lower initial water production rates than well2 at pad3 (light blue versus orange curves in Figure 6(d)). The faster dewatering of well2 at pad3; however, results in lower water production rates than for well 2 at pad 1 after $\sim 3$ years of production (1230 days). While the cumulative gas production for well 2 at pad3 is predicted to be greater than for well 2 at pad 1 after 1 day of production, the cumulative water production for well 2 at pad3 is lower than at pad 1 after $\sim 8$ years of production (2930 days) and 1.1× lower after 25 years of production (light blue versus orange curves in Figure 6(b) and Figure 6(c) and blue curve in Figure 7 (b)). The three laterals at pad 1 produce a maximum of $2.0 \times$ more water than pad3 after 25 years of production (dashed versus solid green curves in Figure 8(c) and black curve in Figure 7(b)).

\subsection{Multi-Well Pad Model with Four Laterals per Pad}

The well geometry for the multi-lateral, multi-well pad model with 4 laterals/pad consists of one $900 \mathrm{~m}$ lateral through the main seam (well1) and three branch laterals with lengths of 610,640 , and $670 \mathrm{~m}$ and at angles of $38^{\circ}, 63^{\circ}$, and $18^{\circ}$ from the main lateral (well2, well4, and well3) at each of the four pads (Figure $1)$.

\subsubsection{Gas Production from Pad 1}

The initial peak gas production rates predicted from the four laterals at pad 1 are higher for the more optimally oriented wells (Figure 9(b)). The optimally-oriented main lateral (well1) predicts it to have the highest initial peak gas production rate and the highest cumulative gas production over the entire 25 year history. The initial peak gas production rate is $1.4 \times$ higher from the main lateral, well1, than the next most optimally-oriented lateral, well3 (red versus orange curves in Figure 9(b)). The difference in cumulative gas production between well1 and well 3 increases to $1.5 \times$ over the 25 year history (red versus orange curves in Figure 9(a) and green curve in Figure 10(a)).

Well3 at pad1, with longer length, more optimal orientation, and lower interference from adjacent pads (i.e. pad3 and pad4) predicts a higher initial gas 
(a)

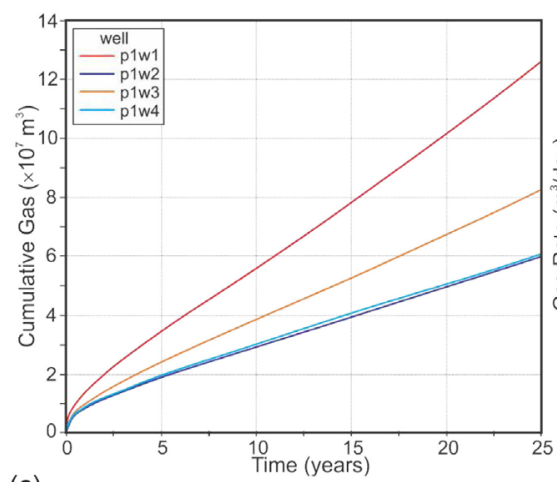

(c)

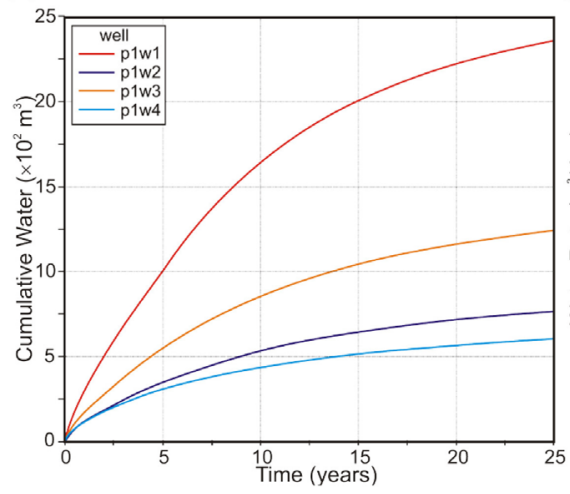

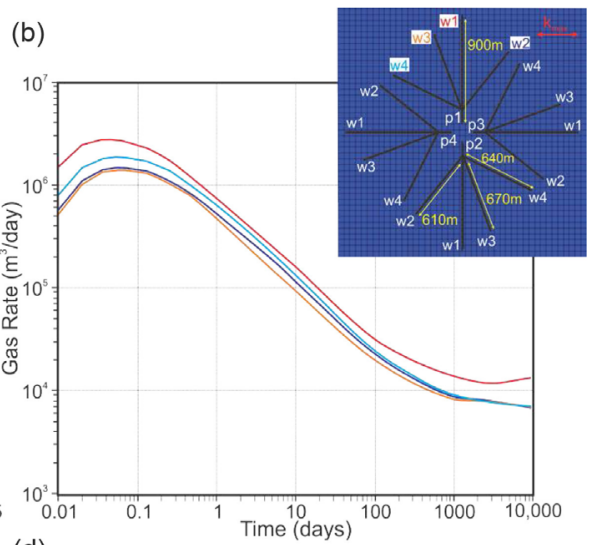

(d)

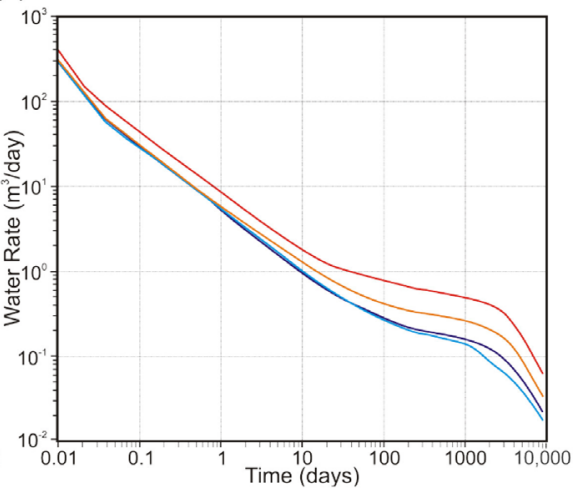

Figure 9. Comparison of the gas (top) and water (bottom) cumulative production (left) and production rates (right) simulated for the 4 laterals at pad1 in the 4 lateral/pad model: well1 (p1w1)-red curves; well2 (p1w2)-blue curves; well3 (p1w3)-orange curves; and well4 (p1w4)-light blue curves. The locations of the laterals are shown on the inset plot of (b). In the inset plot, the maximum permeability is N-S and minimum is $\mathrm{E}-\mathrm{W}$, as shown in Figure 2.

production rate and higher cumulative gas production than well 2 and well4 at pad1. The initial gas production rate for well3 is $1.2 \times$ higher than well2 (orange versus blue curves in Figure 9(b)) and 1.3× higher than for well4 (orange versus light blue curves in Figure 9(b)). The differences in cumulative gas production between well 3 and well2 (orange versus blue curves in Figure 9(a) and blue curve in Figure 10(a)) and between well3 and well4 (orange versus light blue curves in Figure 9(a) and light blue curve in Figure 10(a)) increase with production to $1.4 \times$ at the end of the 25 year history.

The more optimal orientation of well2 than well4 results in well2 having a $1.1 \times$ higher initial gas production rate (blue versus light blue curves in Figure 9(b)); however, the shorter length and faster decline in gas production rates with dewatering for well 2 results in lower gas rates after $\sim 15$ days of production and lower cumulative gas after $\sim 100$ days of production (blue versus light blue curves in Figure 9(a) and pink curve in Figure 10(a)). The cumulative gas production from well4 is a maximum of $3 \%$ higher than from well 2 after 11 years of production. After 11 years of production, well2 has finished dewatering and the gas production rates increase while the rates for well4 continuously decline 
(a)

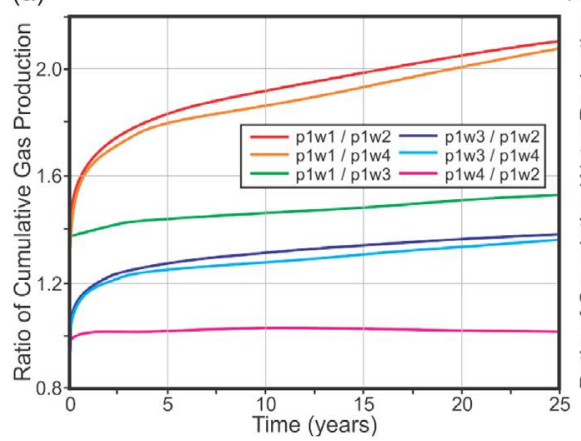

(b)

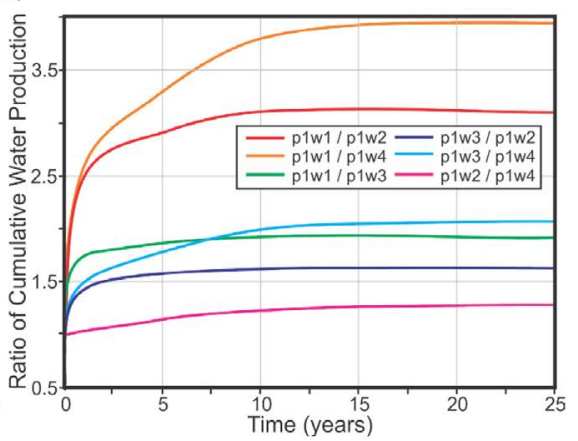

Figure 10. Ratio of cumulative gas production (a) and cumulative water production (b) for well1 (p1w1) versus well2 (p1w2; red curves), well3 (p1w3; green curves), and well4 (p1w4; orange curves) at pad 1; ratio for well3 versus well2 (blue curves) and well4 (light blue curves) at pad1; and ratio for well4 versus well2 (pink curves) for the 4 laterals/pad model.

throughout the 25 year history, slightly decreasing the difference in cumulative gas production between the wells (1.5\% after 25 years of production).

\subsubsection{Water Production from Pad 1}

The more optimally oriented laterals at pad1 predict higher water production than other wells. The faster drainage, due to the longer length and more optimal orientation, of well1 at pad 1 predicts a maximum of $1.9 \times$ more produced water after $\sim 13$ years (4660 days) of production than well3, the next most optimally oriented lateral at pad1 (red versus orange curves in Figure 9 (c) and green curve in Figure 10(b)). The difference in cumulative water production then slightly decreases until the end of the 25 year history, due to the faster dewatering of well1 than well2. Similarly, well1 predicts a maximum of $3.1 \times$ more produced water than well2 after $\sim 14$ years (5170 days) of production (red versus blue curves in Figure 9(c) and red curve in Figure 10(b)) and a maximum of 3.9x more produced water than well4 after $\sim 20$ years (7210 days) of production (red versus light blue curves in Figure 9(c) and orange curve in Figure 10(b)), after which both the differences in cumulative water production between well1 and well 2 and between well1 and well4 decrease slightly until the end of the 25 year history.

Well3, the second most optimally oriented lateral at pad1, predicts a maximum of $2.1 \times$ higher cumulative water production than well 4 after 25 years of production and $1.6 \times$ higher cumulative water production than well 2 after $\sim 17.5$ years (6420 days) of production (orange versus light blue and blue curves in Figure 9(c) and light blue and blue curves in Figure 10(b)). While the lowest gas production predicted for padlis from well2, the cumulative water predicted for well 2 is a maximum of $1.3 \times$ higher than for well 4 after 25 years of production (blue versus light blue curves in Figure 9(c) and pink curve in Figure 10(b)).

\subsubsection{Gas Production from Pad 3}

At pad3, well4 has the most optimal orientation with respect to the coal fracture 
permeability and predicts the highest initial peak gas production rate; however, the poorly-oriented, but longer, main lateral, well1 predicts the highest cumulative gas production over the majority of the 25 year production period. While, the initial peak gas production rate for well 4 is $1.3 \times$ higher than predicted for well 2 and well3, the cumulative gas production is only slightly higher after 25 years of production (1.9\% higher than well 2 and $4.3 \%$ higher than well3; light blue versus blue and orange curves in Figure 11(a) and pink and blue curves in Figure 12(a)).

The initial peak gas production rate for well4 is also slightly higher $(2.7 \%)$ than predicted for the longer, but poorly-oriented main lateral, well1 (light blue versus red curves in Figure 11(b)); however, the gas production rate for well4 is lower than for well 1 after $\sim 100$ days of production. The cumulative gas production for well4 is lower than for well1 after $\sim 2$ years (820 days) and $1.3 \times$ lower at the end of the 25 year history (light blue versus red curves in Figure 11(a) and green curve in Figure 12(a)).

The initial peak gas production rate for well 1 is $1.2 \times$ greater than well 2 and $1.3 \times$ greater than well 3 and the cumulative gas production is a maximum of $1.3 \times$

(a)

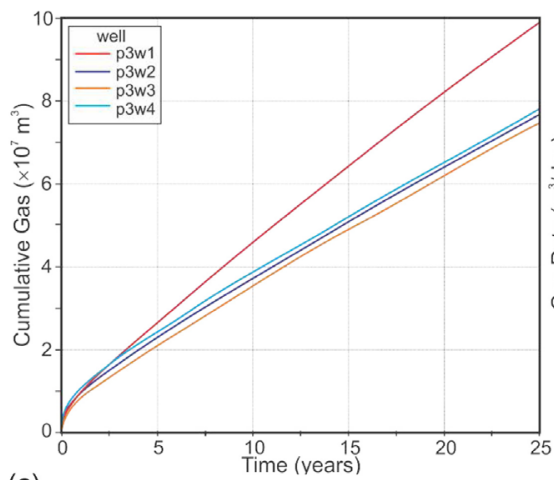

(c)

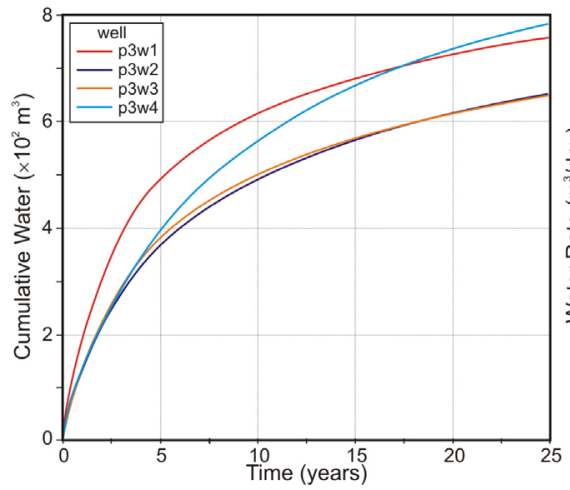

(b)

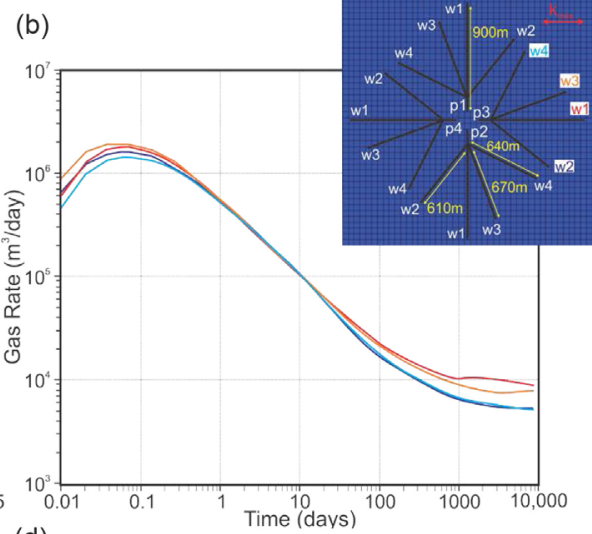

(d)

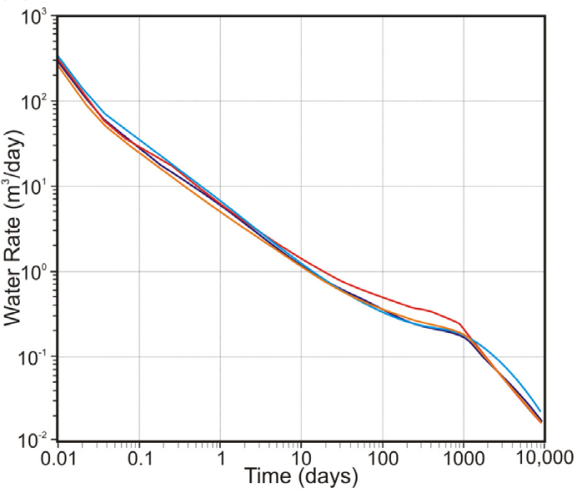

Figure 11. Comparison of the gas (top) and water (bottom) cumulative production (left) and production rates (right) simulated for the 4 laterals at pad3 in the 4 laterals/pad model: well1 (p1w1)—red curves; well2, (p1w2)-blue curves; well3 (p1w3)-orange curves; and well4 (p1w4)-light blue curves. The locations of the laterals are shown on the inset plot of (b). In the inset plot, the maximum permeability is N-S and minimum is E-W, as shown in Figure 2. 
(a)

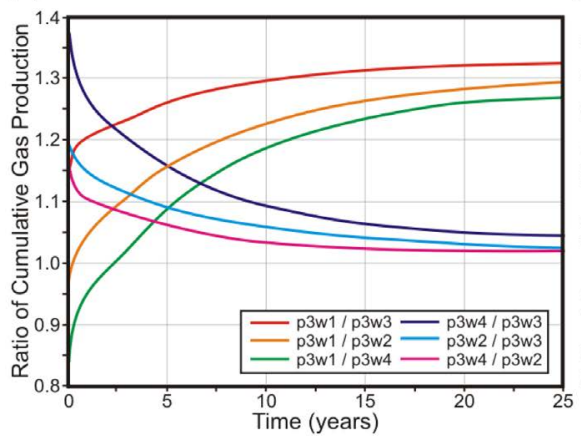

(b)

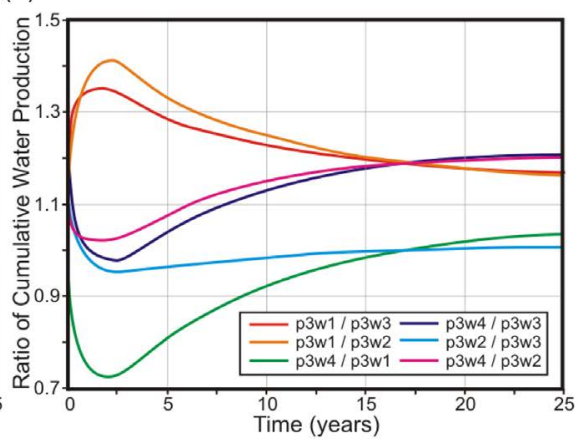

Figure 12. Ratio of cumulative gas production (a) and cumulative water production (b) for well4 ( $\mathrm{p} 3 \mathrm{w} 4)$ versus well1 ( $\mathrm{p} 3 \mathrm{w} 1$; green curves), well2 (p3w2; orange curves), and well3 (p3w3; red curves) at pad 3; ratio for well2 versus well1 (blue curves) and well3 (light blue curves) at pad3; and ratio for well4 versus well2 (pink curves) for the 4 laterals/pad model.

greater than well 2 and $1.5 \times$ greater than for well3 (red versus blue and orange curves in Figure 11(a) and orange and red curves in Figure 12(a)). However, the innermost well1 predicts the fastest dewatering at pad3, which results in lower cumulative gas production than for well 2 from $\sim 1$ to 35 days of production (red versus blue curves in Figure 11(a) and orange curve in Figure 12(a)).

The shorter, but more optimally-oriented lateral, well2, predicts a slightly (4.6\%) higher initial peak gas production rate than well3 (blue versus orange curves in Figure 11(b)). The faster dewatering of well3 than well2 increases the difference in cumulative gas production to a maximum of $1.2 \times$ after $\sim 45$ days then decreases the difference to $2.4 \%$ at the end of the 25 year history (orange versus blue curves in Figure 11(a) and green curve in Figure 12(a)).

\subsubsection{Water Production from Pad 3}

The longest lateral at pad3, well1, which dewaters the fastest, predicts the highest cumulative water production until $\sim 17$ years (6300 days) of production, when the cumulative water production becomes lower than predicted for well4, the most optimally oriented lateral at pad3, which dewaters the slowest. The cumulative water production predicted for well1 is a maximum of $1.4 \times$ higher than for well4 after $\sim 2$ years (800 days) of production and a maximum of $3.2 \%$ lower than well4 at the end of the 25 year history (red versus light blue curves in Figure 11(c) and green curve in Figure 12(b)).

The water production from well 2 and well 3 are similar over the 25 year history, with a maximum difference of $4.7 \%$ after $\sim 2.5$ years (990 days) of production. Initially, well2 predicts the lowest cumulative water production on pad3; however, the cumulative water production from well3 is $0.5 \%$ lower than well 2 at the end of the 25 year history (orange versus blue curves in Figure 11(c) and light blue curve in Figure 12(b)).

After 25 years, the cumulative water production predicted from well 2 and well 3 is a maximum of $1.2 \times$ lower than well 4 and a minimum of $1.2 \times$ lower than 
well1 (Figure 11(c) and Figure 12(b)). While the initial water production rate for well4 is higher than well3, the slower dewatering results is lower cumulative water production from $\sim 1$ to 4 years ( 370 - 1370 days) of production. The cumulative water production from well 1 is maximum of $1.4 \times$ higher than well 1 after $\sim 2$ years (840 days) of production and $1.3 \times$ higher than well1 after $\sim 1.5$ years (630 days) of production (red versus blue and orange curves in Figure 11(c) and orange and red curves in Figure 12(b)).

\subsubsection{Gas Production from Pad 1 versus Pad 3}

The optimally-oriented main lateral at pad1 predicts a $1.5 \times$ higher peak gas production rate than the poorly-oriented main lateral at pad3 (red curve in Figure 9(b) versus Figure 11(b)). The faster dewatering of well1 at pad3 than of well1 at pad1 decreases the difference in cumulative gas production between the wells to $1.2 \times$ after $\sim 13$ years (4690 days) of production (red curve in Figure 9(a) versus Figure 11(a) and red curve in Figure 13(a)). The difference then increases to $1.3 \times$ at the end of the 25 year history, due to the faster depletion of well1 at pad 3 than at pad1.

The more optimally-oriented well 3 at pad1predicts a $1.4 \times$ higher peak gas production rate than for well3 at pad3 (orange curve in Figure 9(b) versus Figure 11(b)), similarly to observed for the main laterals. The faster dewatering of pad3 compared to pad1 decreases the difference in cumulative gas production to $1.1 \times$ after $\sim 14$ years (5140 days) of production and the faster depletion of pad3 then slightly increases the difference to the end of the 25 year history (orange curve in Figure 9(a) versus Figure 11(a) and orange curve in Figure 13(a)).

Well 4 is more poorly-oriented at pad 1 resulting in a $1.3 \times$ lower peak gas production rate than at pad3 (light blue curve in Figure 9(b) versus Figure 11(b)). The faster dewatering of pad 3 compared to pad 1 increases the difference in cumulative gas resulting in $1.3 \times$ higher gas production from well 4 at pad 3 than at pad1 after 25 years of production (light blue curve in Figure 9(a) versus Figure 11(a) and light blue curve in Figure 13(a)).

(a)

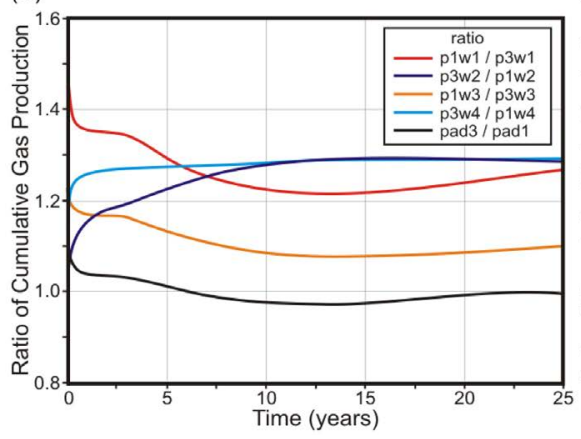

(b)

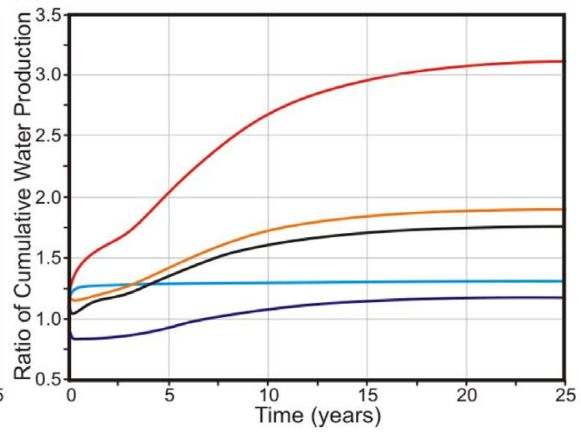

Figure 13. Ratio of cumulative gas production (a) and cumulative water production (b) for well1 at pad1 (p1w1) versus pad3 (p3w1; red curves), well2 at pad3 (p3w2) versus pad1 (p1w2; orange curves), well3 at pad1 (p1w3) versus pad3 (p3w3; green curves), well4 at pad3 (p3w4) versus pad1 (p1w4; blue curves), and for all laterals at pad3 versus all laterals at pad1 (black curves) for the 4 laterals/pad model. 
The difference in orientation is smallest between well 2 at pad 1 and at pad3 than the other laterals. Although the slightly more optimal orientation of well 2 at pad1 ( $\sim 40^{\circ}$ from optimal) than pad3 $\left(\sim 50^{\circ}\right.$ from optimal) results in a $1.1 \times$ higher peak gas production rate, the gas production rate is lower after $\sim 5$ days, due to the faster dewatering of pad3 than pad1 (blue curve in Figure 9 (b) versus Figure 11(b)). The cumulative gas production predicted for well2 at pad3 is higher than for well 2 at pad 3 after the first day of production and the difference between laterals increases, resulting in $1.3 \times$ higher cumulative gas production for well 2 at pad 3 than pad 1 at the end of the 25 year history (blue curve in Figure 9(a) versus Figure 11(a) and blue curve in Figure 13(a)).

The lateral with the highest cumulative gas production for pad1, well1 predicts $2.1 \times$ higher cumulative gas production than well2, the lateral with the lowest cumulative gas production for pad1, at the end of the 25 year production history. In comparison, well1 at pad3, which predicts the highest gas production, predicts $1.3 \times$ higher cumulative gas production than well3. The greater variation in cumulative gas production from the laterals at pad 1 than pad 3 and the prediction that well3 has the second highest gas production at pad1, but the lowest at pad3 results from the higher gas production predicted for well2 and well4 at pad3 than pad1 combined with the slightly lower cumulative gas production predicted for well 3 at pad3 than pad1.

The four laterals at pad1 predict a slightly (4.5\%) higher peak gas production rate than the laterals at pad3 (red solid versus dashed curves Figure $8(\mathrm{~b})$ ). While the production histories are similar for pad1 and pad3, the faster dewatering of the laterals at pad3 results in slightly higher gas rates after $\sim 13$ days of production and higher cumulative gas after $\sim 1$ year (320 days) of production than for the laterals at pad1 (red solid versus dashed curves in Figure 8(a) and black curve in Figure 13(a)). The difference increases to $1.1 \times$ after $\sim 14$ years $(5110$ days) of production, after which the difference slightly decreases until the end of the 25 year production history, due to the faster depletion of the laterals at pad3 than at pad 1 ( $7.5 \%$ after 25 years).

\subsubsection{Water Production from Pad 1 versus Pad 3}

The greater drainage and slower dewatering from the optimally-oriented well 1 at pad1 predicts a maximum of $3.1 \times$ higher cumulative water production at the end of the 25 year history than predicted for the poorly-oriented well1 at pad3 (red curve in Figure 9(c) versus Figure 11(c) and red curve in Figure 13(b)). Similarly, the more optimally-oriented well 3 at pad1 predicts a maximum of $1.9 \times$ higher cumulative water production than predicted for well 3 at pad 3 at the end of the 25 year history (orange curve in Figure 9(c) versus Figure 11(c) and orange curve in Figure 13(b)). In contrast, well4 at pad3 is more optimally oriented than well 4 at pad 1 resulting in a maximum of $1.3 \times$ higher cumulative water production after 25 years (light blue curve in Figure 9(c) versus Figure 11(c) and light blue curve in Figure 13(b)). The slightly more optimal orientation of well 2 at pad 1 predicts a maximum $1.2 \times$ more water after $\sim 5$ months ( 150 days) 
of production than well3 at pad3 (blue curve in Figure 9(c) versus Figure 11(c) and blue curve in Figure 13(b)). The earlier dewatering and faster depletion for well2 at pad3 than at pad1; however, results in higher cumulative water production after $\sim 6.5$ years (2400 days) of production and a maximum of $1.2 \times$ more water after 25 years of production. Similarly to the cumulative gas production, the higher cumulative water production for well1 and well 3 and the lower $\mathrm{cu}$ mulative water production for well 2 and well 4 at pad1 than pad3, results in a much greater variation in the production histories for the laterals at pad 1 than pad3 (4.0× versus $1.2 \times$ difference between laterals with maximum and minimum productions). The resulting total cumulative water production from the four laterals at pad 1 is a maximum of $1.7 \times$ higher than from the four laterals at pad 3 at the end of the 25 year history (red solid versus dashed curves in Figure 8(c) and black curve in Figure 13(b)).

\subsection{Impact of Downspacing}

\subsubsection{Gas Production}

For a pad with an optimally-oriented main lateral (i.e. pad1 and pad2), the model with 3 laterals/pad predicts a $1.9 \times$ higher peak gas production rate than the model with 1 lateral/pad; however, the faster dewatering for the 3 laterals/pad model results in lower gas production rates than the 1 lateral/pad model after $\sim 6$ years (2145 days) of production (blue versus green solid curves in Figure $8(\mathrm{~b})$ ). The difference in cumulative gas production from pad 1 between the 3 lateral/pad and 1 lateral/pad models decreases to $1.1 \times$ after 5 years and $1.1 \%$ after 25 years of production, due to the faster depletion for the 3 laterals/pad model (blue versus green solid curves in Figure 8(a) and red solid curve in Figure 14(a)). Downspacing from a spacing of 3 laterals/pad to 4 laterals/pad predicts a $1.5 \times$ higher peak gas production rate for pad1 (green versus red solid curves in Figure 8(b)). The faster depletion for the 4 laterals/pad model than the 3 laterals/pad model decreases the difference in cumulative gas production from

(a)

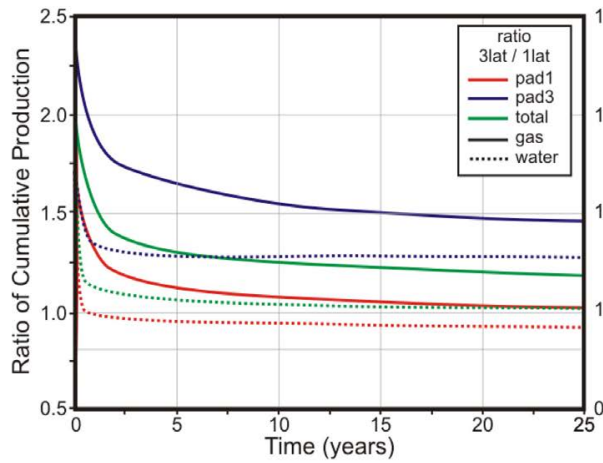

(b)

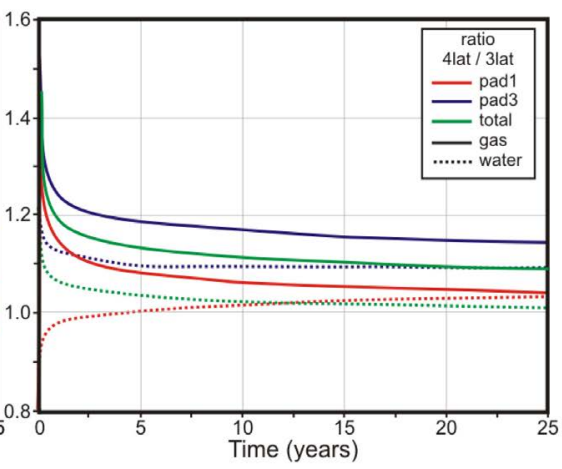

Figure 14. Ratio of cumulative gas production (solid curves) and cumulative water production (dotted curves) from pad1 (red curves), pad3 (blue curves), and the total from the four pads (green curves) for: (a) the models with 3 laterals/pad (3lat) versus 1 later$\mathrm{al} / \mathrm{pad}$ (1lat) and (b) the models with 4 laterals/pad (4lat) versus 3 laterals/pad. 
pad 1 to $8.3 \%$ after 5 years of production and $4.2 \%$ after 25 years of production (green versus red solid curves in Figure 8(a) and red solid curve in Figure 14(b)).

Downspacing has a greater impact on increasing the gas production from pads with the poorly-oriented main laterals (i.e. pad3 or pad4). The initial peak gas production rate predicted from pad 3 for the model with 3 laterals/pad is $2.3 \times$ higher than predicted from pad3 for the 1 lateral/pad model (blue versus green dashed curves in Figure 8(b)). The difference in cumulative gas production from pad 3 between the models with 3 and 1 laterals/pad decreases to $1.6 \times$ after 5 years of production and $1.5 \times$ at the end of the 25 year production history (blue versus green dashed curves in Figure 8(a) and blue solid curve in Figure 14(a)). The peak gas production rate from pad 3 for the model with 4 laterals/pad is $1.6 \times$ higher than for the 3 laterals/pad model (red versus green dashed curves in Figure $8(b)$ ). The difference in cumulative gas production from pad3 between the models with 3 and 4 laterals/pad decreases to $1.2 \times$ after 5 years of production and $1.1 \times$ after 25 years of production (red versus green dashed curves in Figure 8(a) and blue solid curve in Figure 14(b)).

The four pads in the 3 laterals/pad model predict a $2.1 \times$ higher peak gas production rate as a result of downspacing from a 1 lateral/pad spacing (green versus blue curves in Figure 15(b)). The difference in cumulative gas production between the models with 3 and 1 laterals/pad decreases over the production history to $1.3 \times$ after 5 years and $1.2 \times$ after 25 years (green versus blue curves in Figure 15(a) and green solid curve in Figure 14(a)). The initial peak gas production rate from the four pads for the model with 4 laterals/pad is $1.6 \times$ higher than predicted from the four pads for the 3 laterals/pad model (red versus green curves in Figure 15(b)). The difference in cumulative gas production decreases over the production history such that the 4 laterals/pad model is $1.1 \times$ higher after 5 years and $9.0 \%$ higher after 25 years of production than the 3 laterals/pad model (red versus green curves in Figure 15(a) and green solid curve in Figure 14(b)).

\subsubsection{Water Production}

Downspacing from 1 to 3 laterals/pad predicts a $1.9 \times$ higher initial water production rate from pad1 (blue versus green solid curves in Figure 8(d)). However, the cumulative water production predicted for the 3 laterals/pad model is lower than for the 1 lateral/pad model after $\sim 6$ months ( 180 days) of production and the cumulative water production for the 1 lateral/pad model is a maximum of $1.1 \times$ lower than for the 3 laterals/pad model at the end of the 25 year history (blue versus green solid curves in Figure 8(c) and red dotted curve in Figure 14(a)). The initial water production rate from pad 1 for the 4 laterals/pad model is $1.7 \times$ higher than for the 3 laterals/pad model (red versus green solid curves in Figure $8(\mathrm{~d})$ ); however, after $\sim 4$ years (1880 days), the cumulative water production for the 4 laterals/pad model is lower than for the 3 laterals/pad model. After 25 years, the cumulative water production for the 3 laterals/pad model is a 
(a)

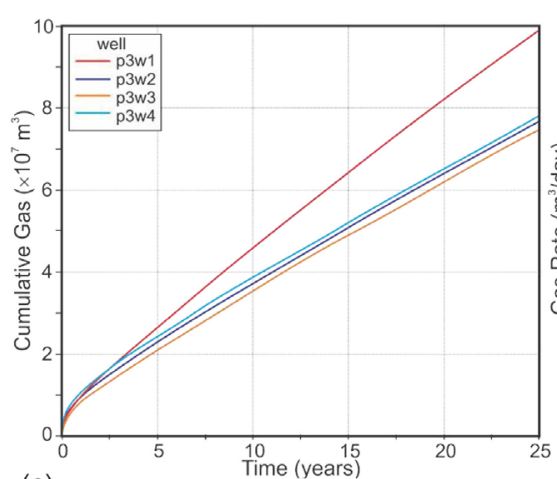

(c)

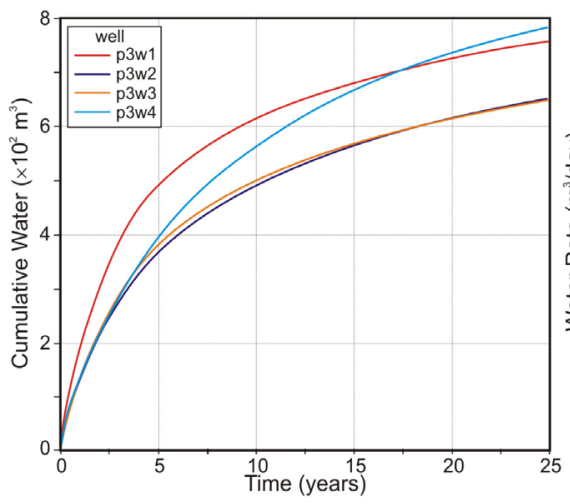

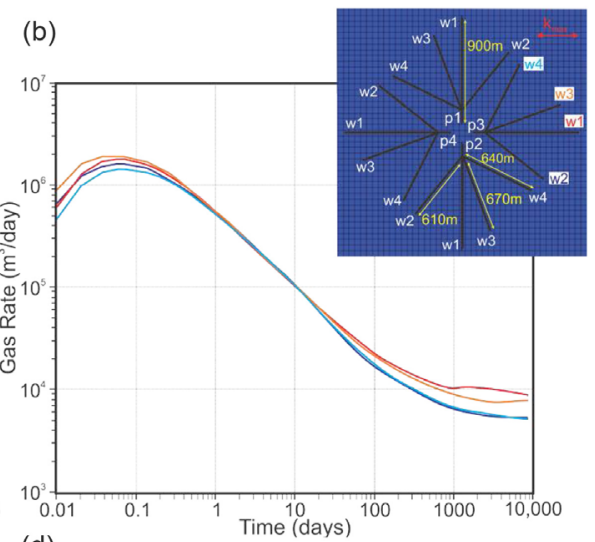

(d)

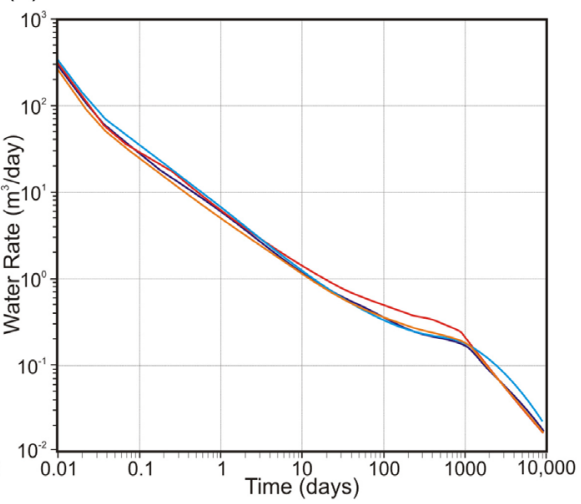

Figure 15. Comparison of the gas (top) and water (bottom) cumulative production (left) and production rates (right) simulated for the 1 lateral/pad (blue curves), 3 laterals/pad (green curves), and 4 laterals/pad (red curves) models.

maximum of $3.2 \%$ higher than for the 4 laterals/pad model (red versus green solid curves in Figure 8(c) and red dotted curve in Figure 14(b)).

Downspacing from a 1 to 3 lateral/pad spacing results in a $2.1 \times$ higher initial water production rate from pad3 (blue versus green dashed curves in Figure $8(d))$ and a decreasing difference in cumulative water production between the two models to $1.3 \times$ after 25 years of production. The 4 laterals/pad model predicts a $1.7 \times$ higher initial water production water from pad 3 and $1.1 \times$ higher cumulative water production after 25 years of production than from pad 3 for the 3 laterals/pad model.

The initial water production rate from the four pads for the 3 laterals/pad model is $2.0 \times$ higher than for the 1 lateral/pad model and the difference in cumulative water production decreases to $1.7 \%$ after 25 years (green versus blue curves in Figure 15(c) and green dotted curve in Figure 14(a)). The four pads for the 4 laterals/pad model predict a $1.7 \times$ higher initial water production rate and $1.0 \%$ higher cumulative water production after 25 years than predicted from the four pads for the 3 laterals/pad model.

\subsection{Produced Coal Gas versus Produced Shale Gas}

The recovered shale gas from the four well pads with a 1 lateral/pad spacing ex- 
ceeds the total recovered coal gas after $\sim 7$ years of production resulting in a ratio of recovered shale to coal gas of 2.4 after 25 years of production (solid versus dotted blue curves in Figure 16(a)). Downspacing initially has a greater impact on the recovery of shale gas than coal gas $(2.6 \times$ versus $2.0 \times$ for downspacing from 1 to 3 laterals/pad and $1.5 \times$ versus $1.4 \times$ for downspacing from 3 to 4 laterals/pad and after 1 month). However, the impact of downspacing from 1 lateral/pad to 3 laterals/pad on the recovered coal gas exceeds the impact on the recovered shale gas after $\sim 3$ years of production (red versus blue curves in Figure 17(a)) and after $\sim 2$ months of production for downspacing from 3 to 4 laterals/pad (red versus blue curves in Figure 18(a)). The impact of downspacing on the coal gas recovery remains slightly greater than on the shale gas recovery until the end of the 25 year history (both $1.2 \times$ after 25 years for downspacing from 1 to 3 laterals/pad and $1.7 \%$ versus $0.5 \%$ for downspacing from 3 to 4 laterals/pad). The resulting ratio of recovered shale to coal gas is lower for the 3 laterals/pad model than the 1 lateral/pad model after $\sim 5$ years of production $(1.5 \%$

(a)

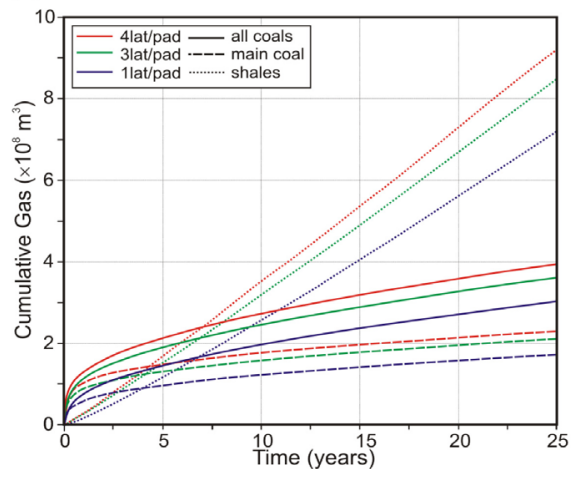

(b)

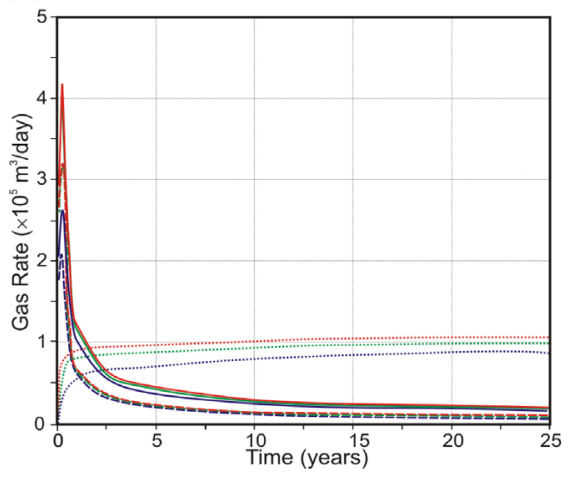

Figure 16. Comparison of cumulative gas recovered (a) and rate of gas recovery (b) from all the coal seams (solid curves), only the Mannville coal seam (dashed curves), and the shale layers (dotted curves) for the 1 lateral/pad (1lat/pad-blue curves), 3 laterals/pad (3lat/pad-green curves), and 4 laterals/pad (4lat/pad-red curves) models.

(a)

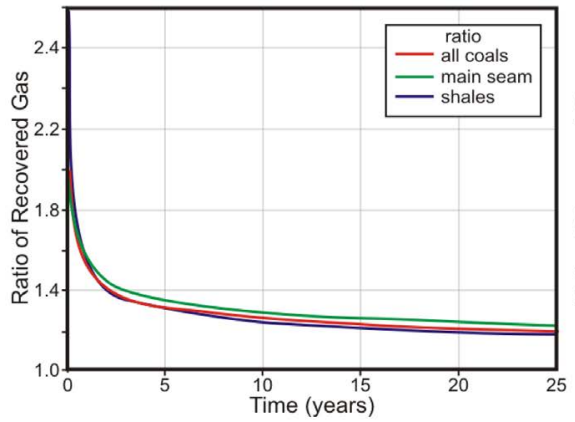

(b)

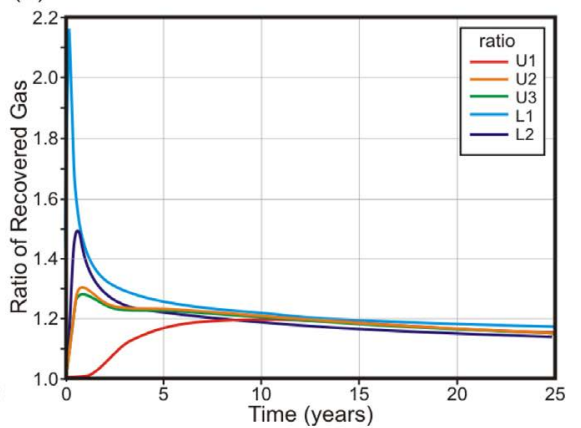

Figure 17. (a) Ratio of recovered gas between the 3 laterals/pad and 1 lateral/pad models from the main coal seam (green curve), all the coal seams (red curve), and the shales (blue curve). (b) Ratio of recovered gas from the upper coal seams: U1 (red curve), U2 (orange curve), and U3 (green curve) and the lower coal seams: L1 (light blue curve) and L2 (dark blue curve) between the 3 laterals/pad and a 1 lateral/pad models. 
(a)

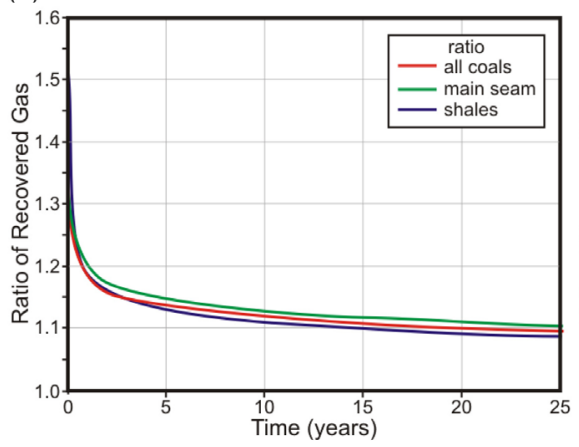

(b)

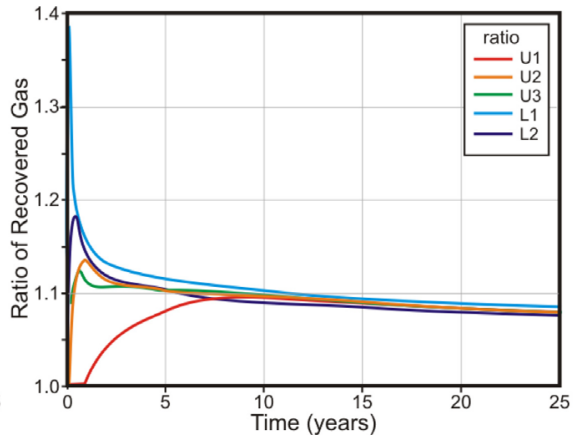

Figure 18. (a) Ratio of recovered gas between the 4 laterals/pad and 3 laterals/pad models from the main coal seam (green curve), all the coal seams (red curve), and the shales (blue curve). (b) Ratio of recovered gas from the upper coal seams: U1 (red curve), U2 (orange curve), and U3 (green curve); and the lower coal seams: L1 (light blue curve) and L2 (dark blue curve) between the 4 laterals/pad and 3 laterals/pad model.

lower ratio after 25 years) and the ratio for the 3 laterals/pad model is lower than the 4 laterals/pad model after $\sim 2$ years of production $(0.65 \%$ lower after 25 years). The recovered shale gas; hence, exceeds the coal gas slightly earlier due to downspacing ( 7 years for all three models; Figure 16(a)).

\subsection{Variation in Produced Gas between Coal Seams}

After 25 years of production, the main coal seam in the 1 lateral/pad model contributes $2.6 \times$ more recovered gas than $\mathrm{L} 1,6.1 \times$ more than $\mathrm{L} 2,13 \times$ more than $\mathrm{U} 3$, $14 \times$ more than U2, and $16 \times$ more than U1 (Figure 19(a) and Table 3). The 3 laterals/pad model predicts a higher contribution of recovered gas from the main coal seam, which results in the greater contribution of produced coal gas than for the 1 lateral/pad model. The contribution of recovered gas from the minor coal seams; however, is lower for the 3 laterals/pad model than for the 1 lateral/pad model (Table 3). Downspacing from 1 to 3 laterals/pad increases the gas recovery from each of the coal seams by $1.2 \times$ after 25 years of production (Figure 17). The maximum difference in the volume of recovered gas, due to downspacing from 1 to 3 laterals/pad, is greater and occurs earlier for coal seams closer to the wellbore $(2.1 \times$ difference for main and L1 after 1 month, compared to $1.5 \times$ difference after 6 months for L2, $1.3 \times$ after 9 months for U2 and U3, and $1.2 \times$ after 9 years for U1; Figure 17(b)). After 25 years of production, the main coal seam in the 3 laterals/pad model contributes $2.7 \times$ more recovered gas than L1, $6.5 \times$ more than L2, $14 \times$ more than U3, $15 \times$ more than U2, and $18 \times$ more than U1 (Figure 19(b) and Table 3).

Downspacing from 3 to 4 laterals/pad, similarly to downspacing from 1 to 3 laterals/pad, results in a higher contribution of recovered gas from the main coal seam and lower contributions from the minor coal seams (Table 3). After 25 years of production, the recovered gas from each of the coal seams for the 4 laterals/pad model is $1.1 \times$ higher than for the 3 laterals/pad model (Figure 18(a)). Downspacing from 3 to 4 laterals/pad also results in a maximum increase in 
(a)

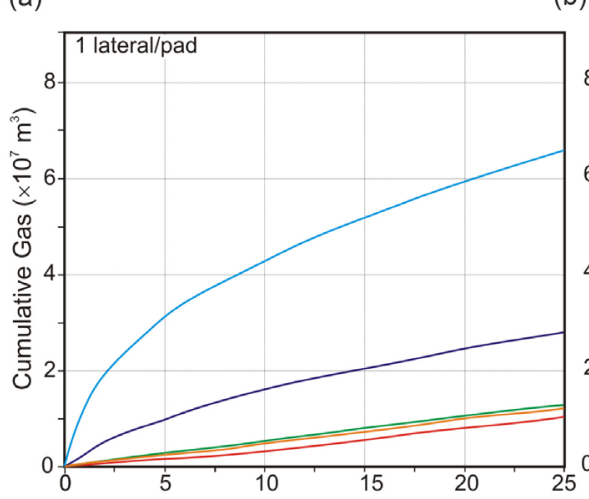

(b)

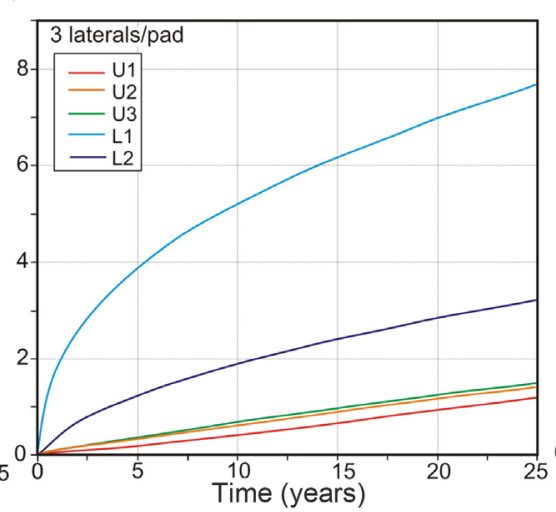

(c)

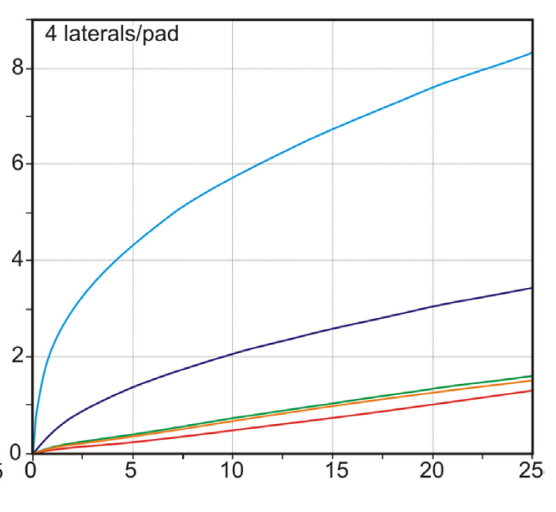

Figure 19. Comparison of cumulative gas recovered (left) and rate of gas recovery (right) from the upper coal seams: U1 (red), U2 (orange), and U3 (green); and the lower coal seams: L1 (light blue) and L2 (blue) for the 1 lateral/pad (a), 3 laterals/pad (b), and 4 laterals/pad (c) models.

Table 3. Relative contribution from coal seams to the produced coal gas (in \%) for 1 month, 1, 5, 15, and 25 years.

\begin{tabular}{|c|c|c|c|c|c|c|}
\hline \multirow{2}{*}{ Time } & \multicolumn{6}{|c|}{1 lateral/pad model } \\
\hline & U1 & $\mathrm{U} 2$ & U3 & L1 & L2 & M \\
\hline $1 \mathrm{mon}$ & 0.40 & 0.089 & 0.31 & 3.2 & 0.49 & 96 \\
\hline 1 & 0.93 & 0.71 & 0.95 & 17 & 3.5 & 77 \\
\hline 5 & 1.1 & 1.8 & 2.0 & 21 & 6.9 & 67 \\
\hline 15 & 2.4 & 3.2 & 3.4 & 22 & 8.7 & 60 \\
\hline \multirow[t]{2}{*}{25} & 3.5 & 4.1 & 4.3 & 22 & 9.3 & 57 \\
\hline & \multicolumn{6}{|c|}{3 laterals/pad model } \\
\hline $1 \mathrm{mon}$ & 0.2 & 0.044 & 0.15 & 3.4 & 0.24 & 96 \\
\hline 1 & 0.62 & 0.60 & 0.81 & 16 & 3.2 & 79 \\
\hline 5 & 1.0 & 1.7 & 1.9 & 21 & 6.4 & 69 \\
\hline 15 & 2.3 & 3.1 & 3.3 & 21 & 8.3 & 62 \\
\hline \multirow[t]{2}{*}{25} & 3.3 & 3.9 & 4.1 & 21 & 8.9 & 58 \\
\hline & \multicolumn{6}{|c|}{4 laterals/pad model } \\
\hline $1 \mathrm{mon}$ & 0.16 & 0.035 & 0.14 & 3.4 & 0.19 & 96 \\
\hline 1 & 0.57 & 0.60 & 0.78 & 16 & 3.1 & 79 \\
\hline 5 & 0.98 & 1.6 & 1.8 & 20 & 6.2 & 69 \\
\hline 15 & 2.2 & 3.0 & 3.3 & 21 & 8.1 & 62 \\
\hline 25 & 3.3 & 3.9 & 4.1 & 21 & 8.8 & 59 \\
\hline
\end{tabular}

recovered gas that is greater and occurs earlier for seams closer to the wellbore (1.4× difference for main and L1 after 1 month compared to $1.4 \times$ for $\mathrm{L} 1$ after $\sim 1$ months, $1.2 \times$ after $\sim 6$ months for L2, 1.1× after $\sim 9$ months for U3, $1.2 \times$ after $\sim 1$ year for U2, and 1.1× after $\sim 11$ years for U1; Figure 18(b)). After 25 years of production, the main coal seam in the 4 laterals/pad model contributes $2.8 \times$ more recovered gas than $\mathrm{L} 1,6.7 \times$ more than $\mathrm{L} 2,14 \times$ more than U3, $15 \times$ more 
than U2, and 18× more than U1 (Figure 19(c) and Table 3).

The recovered gas from the topmost, but thickest of the upper seams, U1, is initially greater than the gas recovered from U2 and U3 for all three models with varying well spacing (Figure 19). The recovered gas from U1 is greater than from U2 and U3 until $\sim 1.5$ years of production for the 1 lateral/pad model, compared to $\sim 1$ year for the 3 laterals/pad model, and $\sim 9$ months for the 4 laterals/pad model. The faster and greater increase in gas production, due to downspacing, for seams closer to the wellbore, results in the shorter time period before the gas recovered from $\mathrm{U} 1$ is less than recovered from $\mathrm{U} 2$ and $\mathrm{U} 3$.

\subsection{Drainage Volume}

The reservoir drainage volumes, approximated by the drawdown in reservoir pressure, for the models with one, three, and four laterals per pad after 1, 5, and 25 years of production are compared in Figures 20-22. The comparison shows the increase in reservoir pressure drawdown in the region around the pads, due to infill drilling. While the drainage volume is only slightly greater for the 3 laterals/pad model than the 1 lateral/pad model, the higher coal and shale recovery for the 3 laterals/pad model is apparent from the greater change in matrix pressure in the section of the model containing the well pads. The higher initial impact of downspacing on the shale gas recovery than coal gas recovery is mainly due to the increased drainage of the interbedded shale layers, S3 and S4, adjacent to the main coal seam. After 5 years of production, increasing the number of laterals per pad from 1 to 3 , increases the ellipsoidal area of significant drainage (decrease in reservoir pressure $>500 \mathrm{kPa}$ ) by $4.9 \%$ and increasing the number of laterals from 3 to 4 increases the drainage area by $1.3 \%\left(2.93 \times 10^{6} \mathrm{~m}^{2}\right.$ versus $3.08 \times 10^{6} \mathrm{~m}^{2}$ versus $\left.3.12 \times 10^{6} \mathrm{~m}^{2}\right)$. For all three models, the significant drainage is restricted to between the top of U2 and the $20 \mathrm{~m}$ of shale below L2 after 5 years of drainage (see Figure 2 for seam geometry). Downspacing from 1 to 3 laterals/pad increases the drainage area by $5.0 \%$ after 25 years of production while downspacing from 3 to 4 laterals/pad increases the drainage area by $0.31 \%$ $\left(6.10 \times 10^{6} \mathrm{~m}^{2}\right.$ versus $6.42 \times 10^{6} \mathrm{~m}^{2}$ versus $\left.6.44 \times 10^{6} \mathrm{~m}^{2}\right)$. After 25 years of production, significant drainage also occurs in $\mathrm{U} 1$ and the $20 \mathrm{~m}$ of shale above $\mathrm{U} 1$, as well as in the $60 \mathrm{~m}$ of shale below $\mathrm{L} 2$.

\section{Conclusions}

Numerical simulations of production from coal measures with anisotropic permeability provide insights to development strategies that are otherwise not readily visualised or predictable. The complex interplay between water production, gas production, contribution from multiple seams and organic rich shales, and impact of well interference, all combined with anisotropic fracture permeability are difficult to predict and some results are counterintuitive. Although no numerical model at this time can truly simulate the actual complexities of the geology, the results using the metrics from the Mannville Group in the producing 


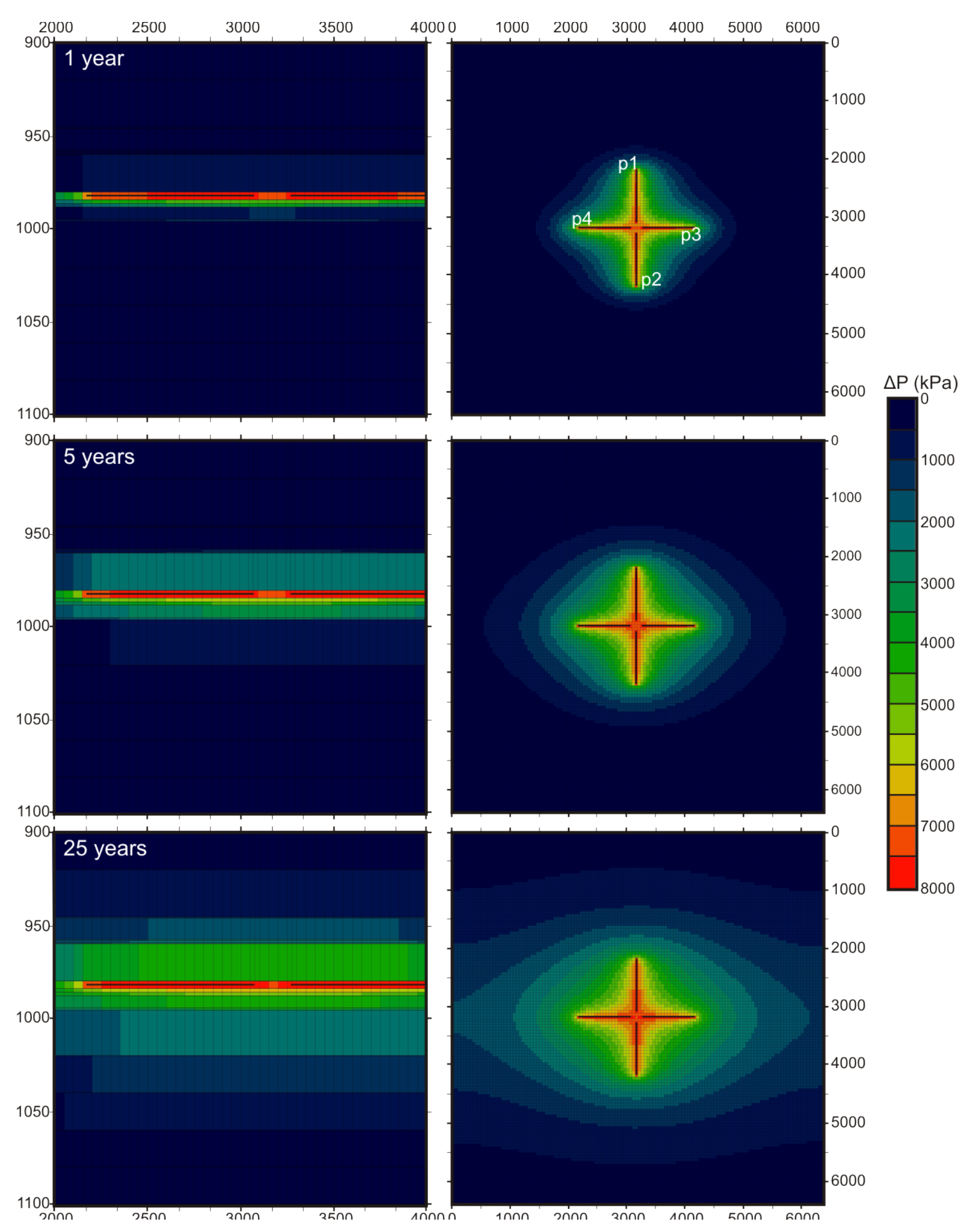

Figure 20. Plots of the change in matrix pressure $(\Delta \mathrm{P}$ in $\mathrm{kPa})$ after 1,5 , and 25 years of production for the 1 lateral/pad model. (Left) Cross-sectional view of a plane through the poorly-oriented laterals on pads 2 and 4 and (right) aerial view of the main coal seam at the depth of the laterals, shown by black lines. 


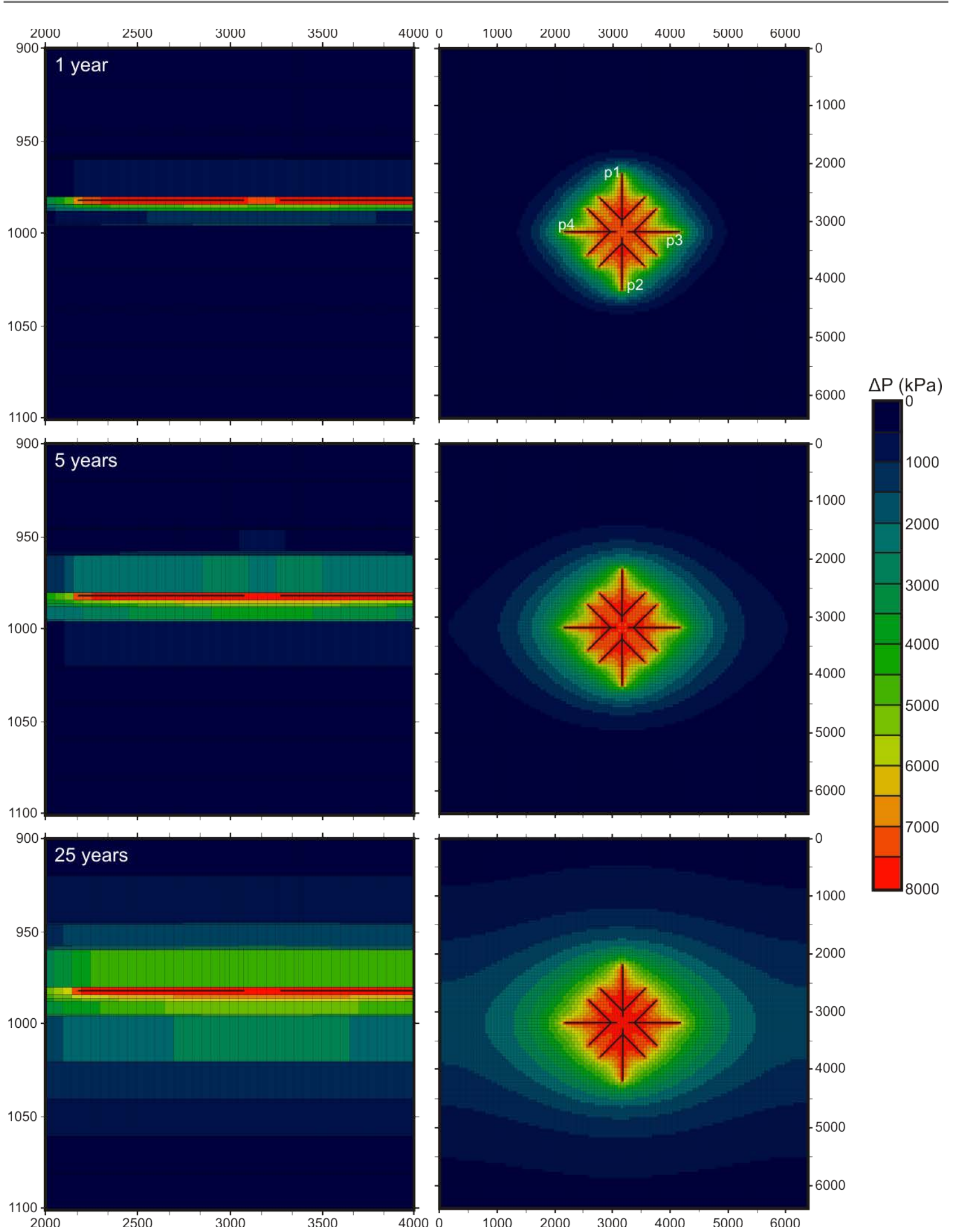

Figure 21. Plots of the change in matrix pressure $(\Delta \mathrm{P}$ in $\mathrm{kPa})$ after 1,5 , and 25 years of production for the 3 laterals/pad model. (Left) Cross-sectional view of a plane through the poorly-oriented laterals on pads 2 and 4 and (right) aerial view of the main coal seam at the depth of the laterals, shown by black lines. 


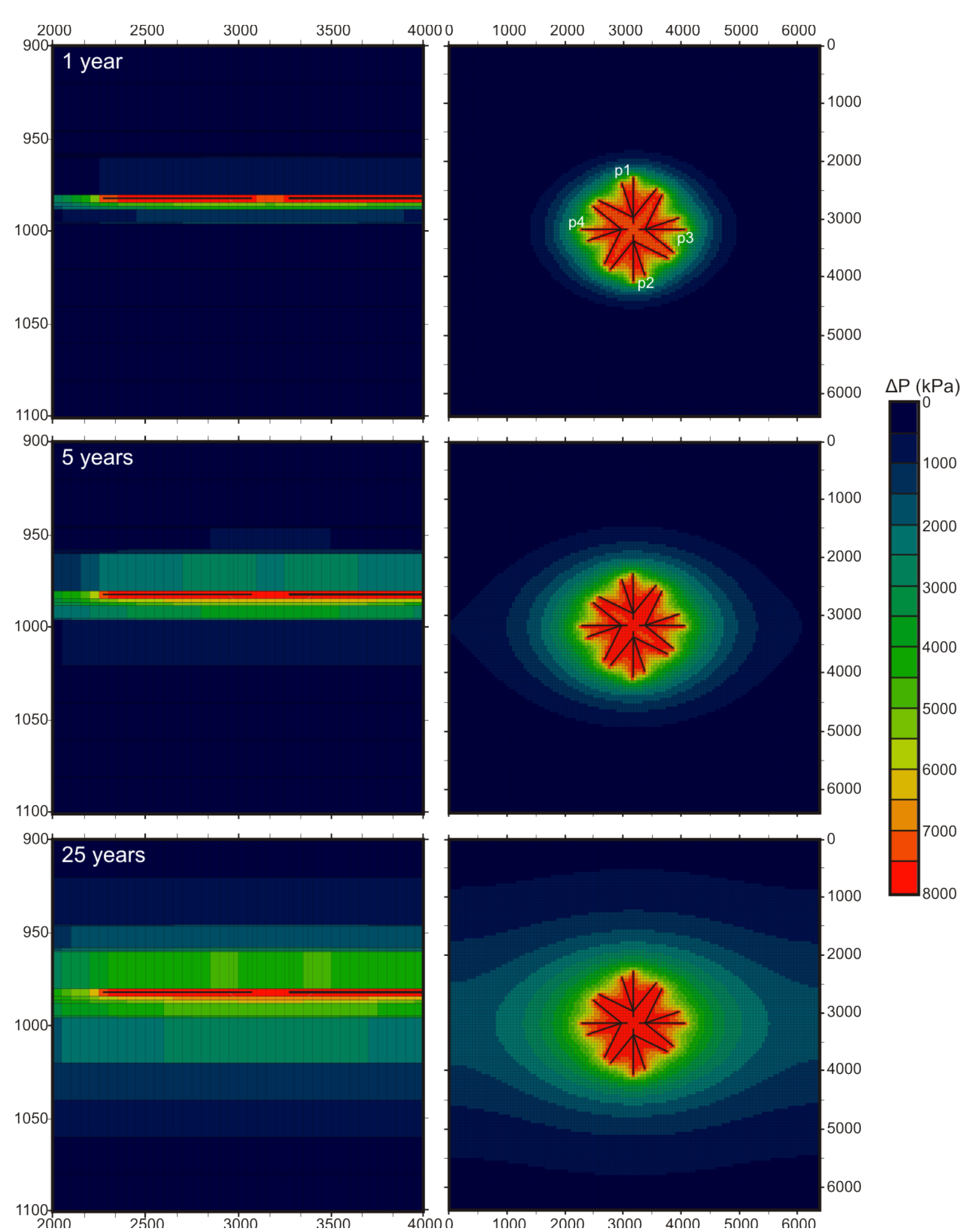

Figure 22. Plots of the change in matrix pressure $(\Delta \mathrm{P}$ in $\mathrm{kPa})$ after 1,5 , and 25 years of production for the 4 laterals/pad model. (Left) Cross-sectional view of a plane through the poorly-oriented laterals on pads 2 and 4 and (right) aerial view of the main coal seam at the depth of the laterals, shown by black lines. 
fairway are instructive and provide a foundation for spacing units, lateral lengths and orientation.

The producability of the gas stored within minor coal seams over- and under-lying the main Mannville coal seams, as well as the gas stored in the shale beds which interbed and over- and under-lie the coal seams has been investigated through a series of numerical simulations of four well-pads on the corners of square mile of land $(1600 \times 1600 \mathrm{~m})$ with decreasing well spacing (from one, three, to four laterals per pad). The cumulative gas production for the 4 laterals/pad model is initially a maximum of $1.6 \times$ higher than for the 3 laterals/pad model. The difference in cumulative gas production between the models with 4 and 3 laterals/pad decreases over the production history and after 25 years, 9.0\% more gas is recovered (black bar in white box in Figure 23(a)). Downspacing from 3 to 1 laterals/pad initially results in a maximum of $2.1 \times$ higher cumulative gas production, after which the difference decreases over the production history to $1.2 \times$ after 25 years (black bar in grey box in Figure 23(a)).

The initial water production rate from the four pads for the 4 laterals/pad model is $1.7 \times$ higher than from the four pads for the 3 laterals/pad model, which is in turn, $2.0 \times$ higher than from the four pads for the 1 lateral/pad model. However, downspacing has less than a $10 \%$ impact on the cumulative water production after $\sim 5$ years of production. The cumulative water production predicted from the 4 laterals/pad model is $1.0 \%$ higher at the end of the 25 year history than the 3 laterals/pad model (black bar in white block in Figure 23(b)), which is $1.7 \%$ higher than the 1 lateral/pad model (black bar in grey box Figure 23(b)).

After 25 years of production, 61\% of the recovered gas is produced from the two optimally-oriented laterals at pad 1 and pad 2 for the 1 lateral/pad model,

(a)

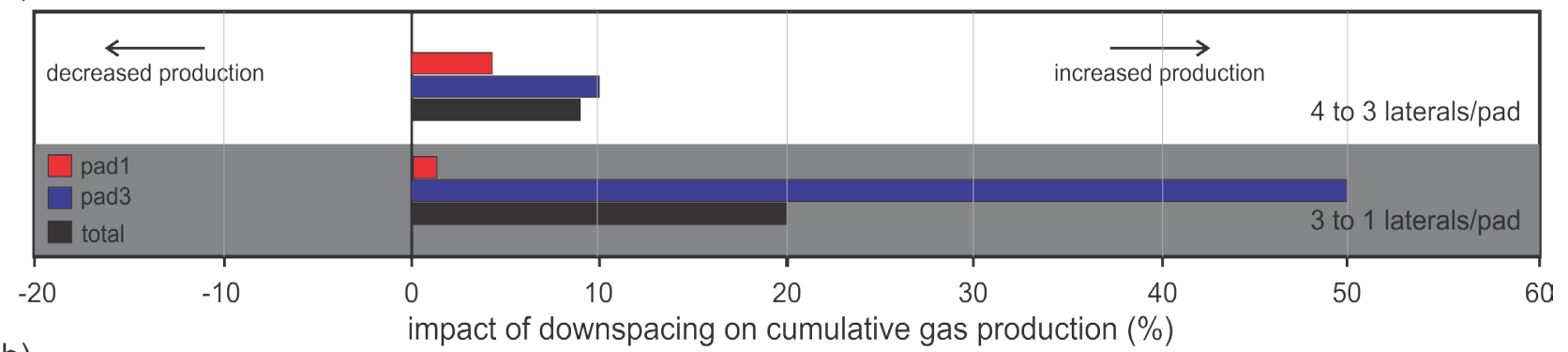

(b)

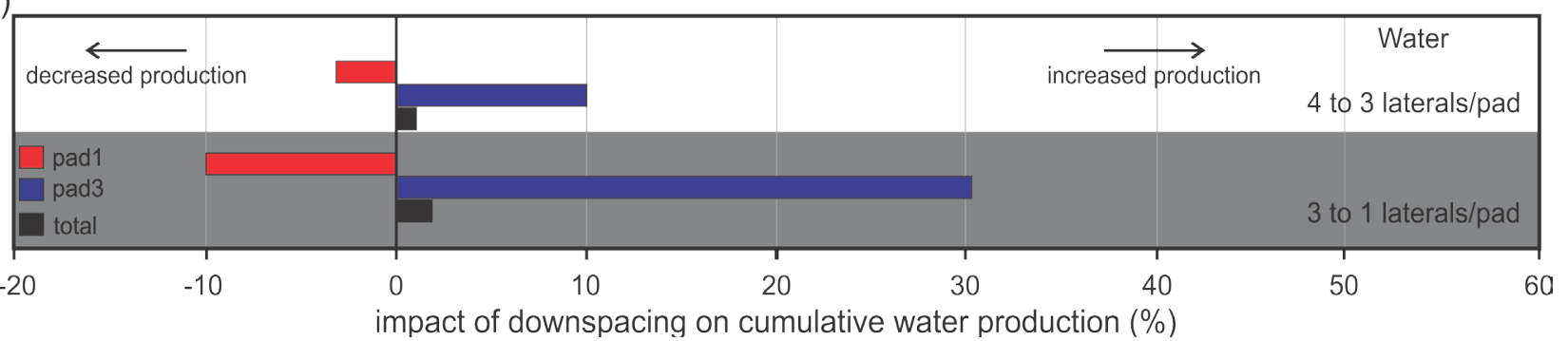

Figure 23. The impact of downspacing from 4 to 3 laterals/pad (white boxes) and from 3 to 1 laterals/pad (grey boxes) on pad1 (red bars), pad3 (blue bars), and the total (i.e. total from the 4 pads; black bars) on the cumulative gas (a) and water (b) productions at the end of the 25 year production period. 
$52 \%$ for the 3 laterals/pad model, and 50\% for the 4 laterals/pad model, due to the assumed fracture permeability anisotropy. Downspacing has a greater impact on increasing the gas production from pads with the poorly-oriented main laterals (pad3) than from the pads with the optimally-oriented main laterals (pad1). The 4 laterals/pad model has a $1.5 \times$ higher initial peak gas production rate from pad 1 and a $4.2 \%$ higher cumulative gas production at the end of the 25 year history than the 3 laterals/pad model (red bar in white box in Figure 23(a)), while the initial peak gas production rate from pad 3 is $1.6 \times$ higher and the cumulative gas production after 25 years is $1.1 \times$ higher (blue bar in white box in Figure 23(a)). The initial peak gas production rate for the 3 laterals/pad model is $1.9 \times$ higher for pad 1 and $2.3 \times$ higher for pad 3 and after 25 years of production, the cumulative gas production is $1.1 \%$ higher for pad1 (red bar in grey box in Figure 23(a)) and 1.5× higher for pad3 (blue bar in grey box in Figure 23(a)). Although downspacing from 3 to 4 laterals/pad has a greater impact on increasing the cumulative gas production from pad1 than downspacing from 1 to 3 laterals/pad ( $4.2 \%$ versus $1.1 \%)$, the lower impact on pad3 $(1.1 \times$ versus $1.5 \times)$ results in a lower total increase the cumulative gas production from the four pads $(9.0 \%$ versus $1.2 \times)$.

The initial water rates from pad1 and pad3 are $1.7 \times$ higher due to downspacing from 3 to 4 laterals/pad and are $1.9 \times$ higher from pad 1 and $2.1 \times$ higher from pad3 due to downspacing from 1 to 3 laterals/pad. Similarly to the results for the gas production, downspacing has little impact on the cumulative water production from the pads with the optimally-oriented laterals (pad1) over the 25-year production history. The cumulative water production from pad 1 for the 3 laterals/pad model is higher than predicted for the 4 laterals/pad model after $\sim 4$ years of production and 3.2\% higher at the end of the 25 year history (red bar in white box in Figure 23(b)), while the 1 lateral/pad model is higher than the 3 laterals/pad model after $\sim 6$ months of production and $1.1 \times$ higher at the end of the 25-year history (red bar in grey box in Figure 23(b)). The cumulative water production from pad 3 for the 4 laterals/pad model is $1.1 \times$ higher than for the 3 laterals/pad model (blue bar in white box in Figure $23(\mathrm{~b})$ ), which is $1.3 \times$ higher than for 1 lateral/pad model (blue bar in grey box in Figure 23(b)) after 25 years of production.

Overall, the results demonstrate that the over and underlying minor coal seams and interbedded organic-rich shales contribute significantly to the producible gas. During the 25-year production history, the higher contribution of produced coal gas predicted due to downspacing results from a higher contribution of recovered gas from the main coal seam, while the contribution from the minor coal seams is lower. The recovered shale gas exceeds the recovered coal gas after $\sim 7$ years of production for the models.

In this paper, we have only considered the impact of pad design on production since economic considerations are dynamic and area specific. Optimising well design and spacing units in field development cannot be made in isolation 
from economics. In this study, we have not added the layer of complexity of economics. Downspacing will always enhance short term production rates, but the net present value of the production has to be weighed against the associated additional capital and operating costs.

\section{Acknowledgements}

This study was made possible through access to data and money from Trident Exploration Corp. and the authors would like to thank Virgil Todea. We are also thankful to CMG for their ongoing support.

\section{References}

[1] Alberta Energy and Utilities Board (2006) Alberta's Energy Reserves 2005 and Supply/Demand Outlook 2006-2015, ST98-2006.

[2] Bustin, A.M.M. and Bustin, R.M. (2011) Horseshoe Canyon and Belly River Coal Measures, South Central Alberta: Part 2-Modeling Reservoir Properties and Producible Gas. Bulletin of Canadian Petroleum Geology, 59, 235-260. https://doi.org/10.2113/gscpgbull.59.3.235

[3] Berhame, H. (2009) CBM Potential of the Alberta Plains-Net Thickness of the Mannville Coal Zone (GIS Dataset). Alberta Geological Survey, Digital Data 2009-0043.

[4] Taylor, M., Hancock, B. and Bustin, R.M. (2008) Coalbed Methane Development in Canada, Challenges and Opportunities. International Gas Congress of 2008, Oslo, 6-14 August 2008.

[5] Bustin, A.M.M. and Bustin, R.M. (2016) Contribution of Non-Coal Facies to the Total Gas-in-Place in Mannville Coal Measures, Central Alberta. International Journal of Coal Geology, 144-145, 69-81. https://doi.org/10.1016/j.coal.2015.12.002

[6] Bustin, A.M.M. and Bustin, R.M. (2016a) Total Gas-in-Place, Gas Composition and Reservoir Properties of Coal of the Mannville Coal Measures, Central Alberta. International Journal of Coal Geology, 153, 127-143.

[7] Bustin, A.M.M. and Bustin, R.M. (2016) Contribution to Gas Production from Minor Coal Seams and Adjacent Shales: Numerical Modelling Results for the Mannville Coal Measures, South Central Alberta. Journal of Petroleum Technology, Unpublished.

[8] Bustin, A.M.M. and Bustin, R.M. (2017) Impact of Reservoir Properties on the Prodution of the Mannville Coal Measures, South Central Alberta from a Numerical Modelling Parametric Analysis. Engineering, 9, 291-327. https://doi.org/10.4236/eng.2017.93016

[9] Gentzis, T. and Bolen, D. (2008) The Use of Numerical Simulation in Predicting Coalbed Methane Producability from the Gates Coals, Alberta Inner Foothills, Canada: Comparison with Mannville Coal Production in the Alberta Syncline. International Journal of Coal Geology, 74, 167-258. 